\author{
Marquette University \\ e-Publications@Marquette
}

2007

\title{
BORAZANs: Tunable Fluorophores Based on 2-(Pyrazolyl)aniline Chelates of Diphenylboron
}

\author{
Brendan J. Liddle \\ Marquette University \\ Rosalice M. Silva \\ Marquette University \\ Tyler James Morin \\ Marquette University \\ Felipe P. Macedo \\ Marquette University \\ Ruchi Shukla \\ Marquette University
}

See next page for additional authors

Follow this and additional works at: https://epublications.marquette.edu/chem_fac

Part of the Chemistry Commons

\section{Recommended Citation}

Liddle, Brendan J.; Silva, Rosalice M.; Morin, Tyler James; Macedo, Felipe P.; Shukla, Ruchi; Lindeman, Sergey V.; and Gardinier, James R., "BORAZANs: Tunable Fluorophores Based on 2-(Pyrazolyl)aniline Chelates of Diphenylboron" (2007). Chemistry Faculty Research and Publications. 629.

https://epublications.marquette.edu/chem_fac/629 


\section{Authors}

Brendan J. Liddle, Rosalice M. Silva, Tyler James Morin, Felipe P. Macedo, Ruchi Shukla, Sergey V. Lindeman, and James R. Gardinier 


\section{Marquette University \\ e-Publications@Marquette}

\section{Chemistry Faculty Research and Publications/College of Arts and Sciences}

This paper is NOT THE PUBLISHED VERSION; but the author's final, peer-reviewed manuscript. The published version may be accessed by following the link in the citation below.

Journal of Organic Chemistry, Vol. 72, No. 15 (2007): 5637-5646. DOI. This article is (C) American Chemical Society and permission has been granted for this version to appear in $\mathrm{e}-$ Publications@Marquette. American Chemical Society does not grant permission for this article to be further copied/distributed or hosted elsewhere without the express permission from American Chemical Society.

\section{BORAZANs: Tunable Fluorophores Based on 2-(Pyrazolyl)aniline Chelates of Diphenylboron}

\section{Brendan J. Liddle}

Department of Chemistry, Marquette University, Milwaukee, WI

Rosalice M. Silva

Department of Chemistry, Marquette University, Milwaukee, WI

Tyler J. Morin

Department of Chemistry, Marquette University, Milwaukee, WI Felipe P. Macedo

Department of Chemistry, Marquette University, Milwaukee, WI Ruchi Shukla

Department of Chemistry, Marquette University, Milwaukee, WI Sergey V. Lindeman

Department of Chemistry, Marquette University, Milwaukee, WI James R. Gardinier*

Department of Chemistry, Marquette University, Milwaukee, WI 


\section{Abstract}

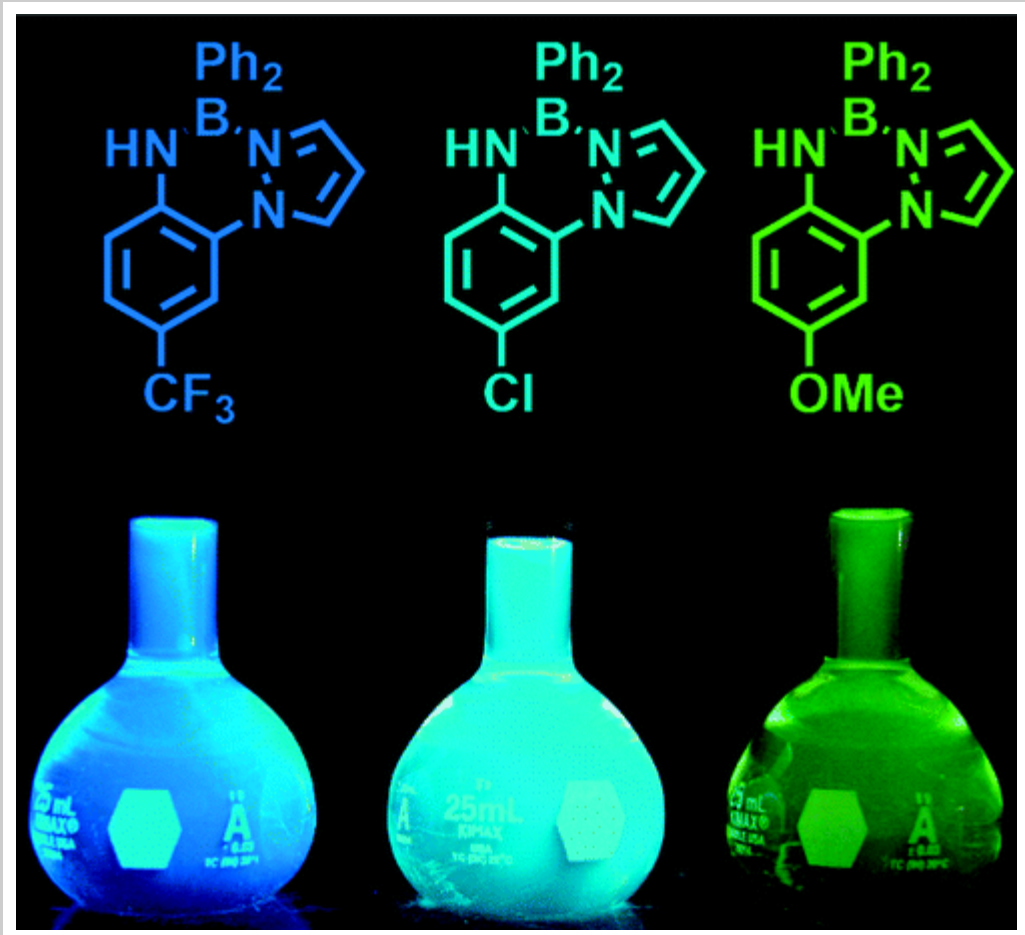

The reaction between 2-pyrazolyl-4-X-anilines, $\mathrm{H}\left(\mathrm{pzAn}^{\mathrm{X}}\right)$, (X = para-OMe (L1), Me (L2), H (L3), $\mathrm{Cl}$ (L4), $\mathrm{CO}_{2} \mathrm{Et}(\mathbf{L 5}), \mathrm{CF}_{3}$ (L6), CN (L7)) and triphenylboron in boiling toluene affords the respective, highly emissive $N, N^{\prime}$-boron chelate complexes, $\mathrm{BPh}_{2}\left(\operatorname{pzAn}^{\mathrm{X}}\right)(\mathrm{X}=$ para-OMe (1), $\mathrm{Me}(2), \mathrm{H}(3), \mathrm{Cl}(4), \mathrm{CO}_{2} \mathrm{Et}(5), \mathrm{CF}_{3}(6), \mathrm{CN}(7)$ ) in high yield. The structural, electrochemical, and photophysical properties of the new boron complexes can be fine-tuned by varying the electron-withdrawing or -donating power of the para-aniline substituent (delineated by the substituent's Hammett parameter). Those complexes with electron-withdrawing para-aniline substituents such as $\mathrm{CO}_{2} \mathrm{Et}(5), \mathrm{CF}_{3}(6)$, and $\mathrm{CN}(7)$ have more planar chelate rings, more 'quinoidal' disortion in the aniline rings, greater chemical stability, higher oxidation potentials, and more intense ( $\varphi_{F}=0.81$ for 7 in toluene), higher-energy (blue) fluorescent emission compared to those with electron-donating substituents. Thus, for $\mathbf{1}$ the oxidation potential is $0.53 \mathrm{~V}$ versus $\mathrm{Ag} / \mathrm{AgCl}$ (compared to $1.12 \mathrm{~V}$ for 7 ), and the emission is tuned to the yellowgreen but at an expense in terms of lower quantum yields ( $\varphi_{F}=0.07$ for 1 in toluene) and increased chemical reactivity. Density functional calculations (B3LYP/6-31G*) on PM3 energyminimized structures of the ligands and boron complexes reproduced experimentally observed data and trends and provided further insight into the nature of the electronic transitions.

\section{Introduction}

The design of electroactive luminophores is of fundamental and practical interest for a range of important applications from OLED devices to immunoassaying. ${ }^{1}$ Particularly noteworthy are the electroactive boron-dipyrrin (or BODIPY) ${ }^{2}$ compounds whose intense narrow absorption bands and high quantum yields of fluorescence have been exploited in many useful applications such as in laser dyes, ${ }^{3}$ in sensors and switches, ${ }^{4}$ in biological imaging and assaying, ${ }^{5}$ and even in light-harvesting and photovoltaics. ${ }^{6}$ The successful use of these boron compounds in such a wide variety of applications has incited research interest into the synthesis and study of other photoactive $\mathrm{N}, \mathrm{N}^{-7 a-9}$ and related ${ }^{7 \mathrm{~h}, \mathrm{i}} \mathrm{N}, \mathrm{O}-$ chelates of boron. Ideally, 
any new boron-containing fluorescent dyes would be easily prepared, be stable, and have electronic properties with broad-spectrum tunability that would open the door for potential new applications.

We were intrigued by the recent reports of high yield syntheses of 2-(pyrazolyl)aniline derivatives by copper-catalyzed cross-coupling reactions, ${ }^{8}$ as these compounds could be envisioned as N,N-chelate ligands to boron or other Lewis acids. In fact, the coordination chemistry of a few 2-(pyrazolyl)aniline derivatives has sporadically been reported, ${ }^{9}$ but little is known about the electronic properties of the ligands or the complexes thereof. We have recently discovered that the 2-(pyrazolyl)anilines can serve as an interesting new class of fluorescent 'turn-on' sensing ligands giving intense emission, both in solution and the solid state, on reaction with certain Lewis acids. As the first part in a series, we report our findings concerning a new class of highly emissive (tunable from blue to yellow-green) boron fluorophores, the BORAZANs (boron azo-anilines), that are obtained from the reaction between triphenylboron and various 2-(pyrazolyl)anilines. For simplicity, we will use shorthand notation when referring to the ligands and BORAZAN complexes. The pyrazolyl-aniline ligands can be represented by the formula $\mathrm{H}\left(p z^{y} A n^{x}\right)$ where $p z=$ pyrazolyl, $A n=$ aniline, $y$ and $x$ represent substitution on the corresponding component; the unsubstituted parent compound has no superscripts ( $\mathrm{y}$ or $\mathrm{x}$ ) and an un-numbered superscript refers to substitution at the 4position of the respective fragment.

\section{Results and Discussion}

Synthesis. The desired BORAZAN dyes were prepared as outlined in Scheme 1. A minor modification of Buchwald's ${ }^{8 a}$ and Taillefer's ${ }^{8 b-e}$ copper-catalyzed $\mathrm{N}$-arylation reaction between pyrazole and 2-bromoanilines ${ }^{10,11}$ was exploited in the current work. In our hands the use of xylenes as a solvent gave the highest yields of product, although the exact mechanism for enhanced yields is unclear. When the reaction was performed either neat or in refluxing DMF, we encountered extensive decomposition and difficulties in product separation. When toluene rather than xylenes was used (over the same time period), lower yields were obtained likely due to lower reaction temperatures. It is noted that in cases where only modest yields of L1-L7 were obtained (using xylenes or toluene), the reaction simply appeared incomplete (TLC), with no identifiable side products. The ensuing reaction of the appropriate 2pyrazolylaniline ligand with triphenylboron proceeds to completion to give the desired BORAZAN within a few hours in refluxing toluene. If the reaction is performed in hexanes, the reaction is incomplete, giving, at first, a precipitate with distinct bright cyan luminescence (presumably a simple Lewis acid-base adduct, $\mathrm{Ph} 3 \mathrm{~B} \cdot\left[\left(\mu-\mathrm{NH}_{2}\right)-p-(\mathrm{X}) \mathrm{C}_{6} \mathrm{H}_{3}(\mathrm{pz})\right]$ ) and then only a mixture on further heating. The higher reflux temperature of toluene compared to hexanes is apparently necessary to drive the reaction to completion in a reasonable time period. 


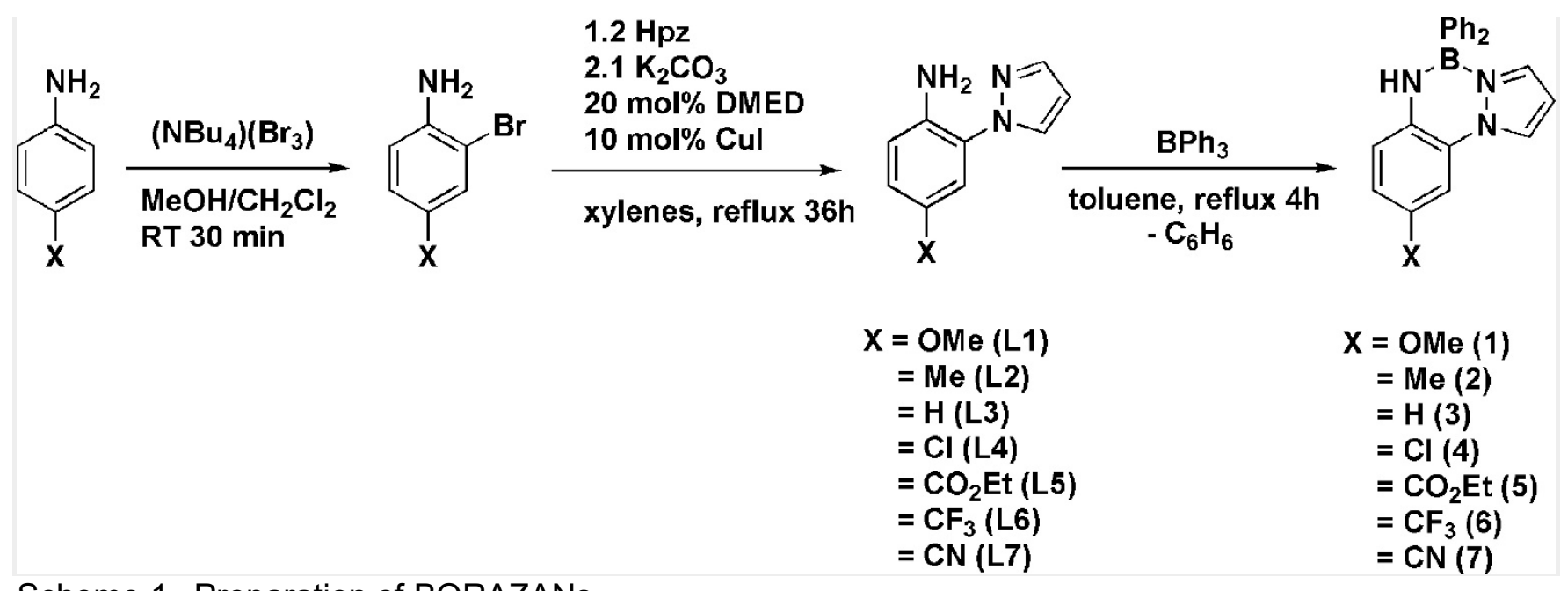

Scheme 1. Preparation of BORAZANs

The BORAZAN dyes exhibit a range of air-stability depending on both the nature of the paraaniline substituent and the physical state. Thus, the air stability of the dyes (toward hydrolysis both in the solid state and in solution) is significantly greater for derivatives with electronwithdrawing para-aniline substituents $\left(\mathrm{CO}_{2} \mathrm{Et}, \mathrm{CF}_{3}, \mathrm{CN}\right)$ compared to derivatives with more electron-donating substituents (OMe, Me). For the usual kinetic reasons, the solids are more resistant to (air) hydrolysis than when in solution. The BORAZANs 5-7 with more electronwithdrawing groups can be stored as solids at atmospheric conditions for weeks to months before detectable hydrolysis products (notably the free ligand) can be observed by NMR, but the remaining derivatives begin decomposing over the period of days to weeks. Thus, the dyes are best stored as solids in a desiccator or in a drybox. The BORAZANs are soluble in most organic solvents except hexanes and lower alkanes, in which cases they are only slightly soluble. When protected from atmospheric moisture and when using dried, distilled solvents, solutions of BORAZANs are indefinitely stable. However, when hydrocarbon solutions are exposed to atmospheric conditions, BORAZANs 5-7appear stable whereas 1-4 slowly degrade by hydrolysis over the period of days to weeks. The rate of decomposition is greatly accelerated to a period of hours for 1-4 in Lewis basic solvents, owing to the greater hygroscopic nature of these solvents compared to hydrocarbons. Again, the rate of solvolysis increases with increasing electron-donating character of the aniline's para-substituent. For example, $\mathrm{Ph}_{2} \mathrm{~B}\left(\mathrm{pzAn}^{\mathrm{CF} 3}\right)$ (6) appears quite stable (retaining its fluorescence) over a period of weeks after dissolution in absolute ethanol; however, both $\mathrm{Ph}_{2} \mathrm{~B}\left(\mathrm{pzAn}^{\mathrm{OMe}}\right)(\mathbf{1})$ and $\mathrm{Ph}_{2} \mathrm{~B}\left(\mathrm{pzAn}^{\mathrm{Me}}\right)$ (2) decompose within several minutes after dissolution. Chlorinated solvents must be rigorously treated to eliminate the presence of trace $\mathrm{HCl}$ which is also deleterious.

Solid-State Structure. The molecular structures of the free ligand $\mathrm{H}\left(\mathrm{pzAn}^{\mathrm{Me}}\right), \mathrm{L} 2$ and its BORAZAN derivative $\mathrm{Ph}_{2} \mathrm{~B}\left(\mathrm{pzAn}^{\mathrm{Me}}\right)$ (2) are found in Figure 1. Three other BORAZANs $\mathrm{Ph}_{2} \mathrm{~B}\left(\mathrm{pzAn}^{\mathrm{X}}\right)\left[\mathrm{X}=\mathrm{MeO}(\mathbf{1}), \mathrm{CF}_{3}(\mathbf{6})\right.$, and $\left.\mathrm{CN}(7)\right]$ are structurally very similar to 2 , and their structures are provided in the Supporting Information. Certain intramolecular geometric features of the structurally characterized compounds that are pertinent to the ensuing discussion, especially concerning the origin of the electronic tunability of the fluorescent dyes, are summarized in Table 1. Also, the lessons learned from a thorough examination of the structures may help in the future 'molecular design' of other Lewis acid chelate complexes of the 2-(pyrazolyl)aniline scaffold. In the solid state, all of the BORAZANs possess only $C_{1}$ symmetry due to distorted tetrahedral boron and puckered (half-chair type) chelate rings that distinguish 'axial' and 'equatorial' phenyl groups on boron. Throughout the series 
$\mathrm{Ph}_{2} \mathrm{~B}\left(\mathrm{pzAn}^{\mathrm{X}}\right)\left[\mathrm{X}=\mathrm{MeO}(\mathbf{1}), \mathrm{Me}(2), \mathrm{CF}_{3}(6), \mathrm{CN}(7)\right]$, the average $\mathrm{B}-\mathrm{N}$ and $\mathrm{B}-\mathrm{C}$ bond distances are rather unvarying, with the average $B-N$ distance $(1.57 \AA)$ being $0.05 \AA$ shorter than the average $B-C$ distance (1.62 $\AA$ ). For each BORAZAN, two inequivalent $B-N$ and $B-C$ bond distances can be differentiated. As can be seen from Table 1, the $\mathrm{B}-\mathrm{N}$ (anilino) bonds are ca. $0.06 \AA$ shorter than the $\mathrm{B}-\mathrm{N}(\mathrm{pz})$ formal dative bonds while the 'equatorial' $\mathrm{B}-\mathrm{C}$ bonds are about $0.01 \AA$ shorter than the 'axial' bonds. It can also be seen that within the BORAZAN series there are structural trends that correlate well with the primitive Hammett parameters, $\sigma_{p},{ }^{12}$ of the para-aniline substituents, as might be expected. For instance, the 'quinoidal' distortion of the aniline unit appears to increase with increasing electron-withdrawing character of the para-X substituents, inferred by both the decrease in the $N(3)-C(9)$ bond distance (increasing double-bond character) $\left[1.390,1.388,1.365,1.354 \AA\right.$ for $\mathrm{X}=\mathrm{OMe}, \mathrm{Me}, \mathrm{CF}_{3}, \mathrm{CN}$, respectively], and the average distance for $C(4)-C(5)$ and $C(7)-C(8)$ bonds [1.390, 1.388, $1.383,1.374 \AA$ for $\mathrm{X}=\mathrm{OMe}, \mathrm{Me}, \mathrm{CF}_{3}, \mathrm{CN}$, respectively] (see Figure 1 for atom labeling). There is also a concomitant increase in planarity of the three-coordinate aniline nitrogen, evident from the sum of the angles about $N(3)$ of $343.8^{\circ}, 344.2^{\circ}, 350.8^{\circ}, 353.2^{\circ}$ for $\mathbf{1}, \mathbf{2}, \mathbf{6}$, and 7 , respectively (for an 'ideal' trigonal-pyramidal nitrogen the sum would be $328.5^{\circ}$ while in planar nitrogen the sum would be $360^{\circ}$ ). Thus, the electron-withdrawing groups appear to reduce the stereochemical influence of the aniline nitrogen lone pair. Perhaps as a consequence of these structural influences, the degree of chelate ring-puckering, best measured by the normal vector originating from boron extending to the mean plane of the $\mathrm{C}_{6} \mathrm{~N}$ framework of the aniline moiety ( $0 \AA$ for a planar chelate ring), decreases with increasing electron-withdrawing power of paraaniline substituents $(0.82,0.81,0.76$, and $0.63 \AA$ for $\mathbf{1}, \mathbf{2}, \mathbf{6}$, and $\mathbf{7}$, respectively). Alternate descriptors of ring-puckering (such as the dihedral angle between the mean plane of the aniline group and the plane defined by pyrazolyl-nitrogen, boron, and aniline-nitrogen atoms) give identical trends, but are complicated by other structural distortions, as described below. 

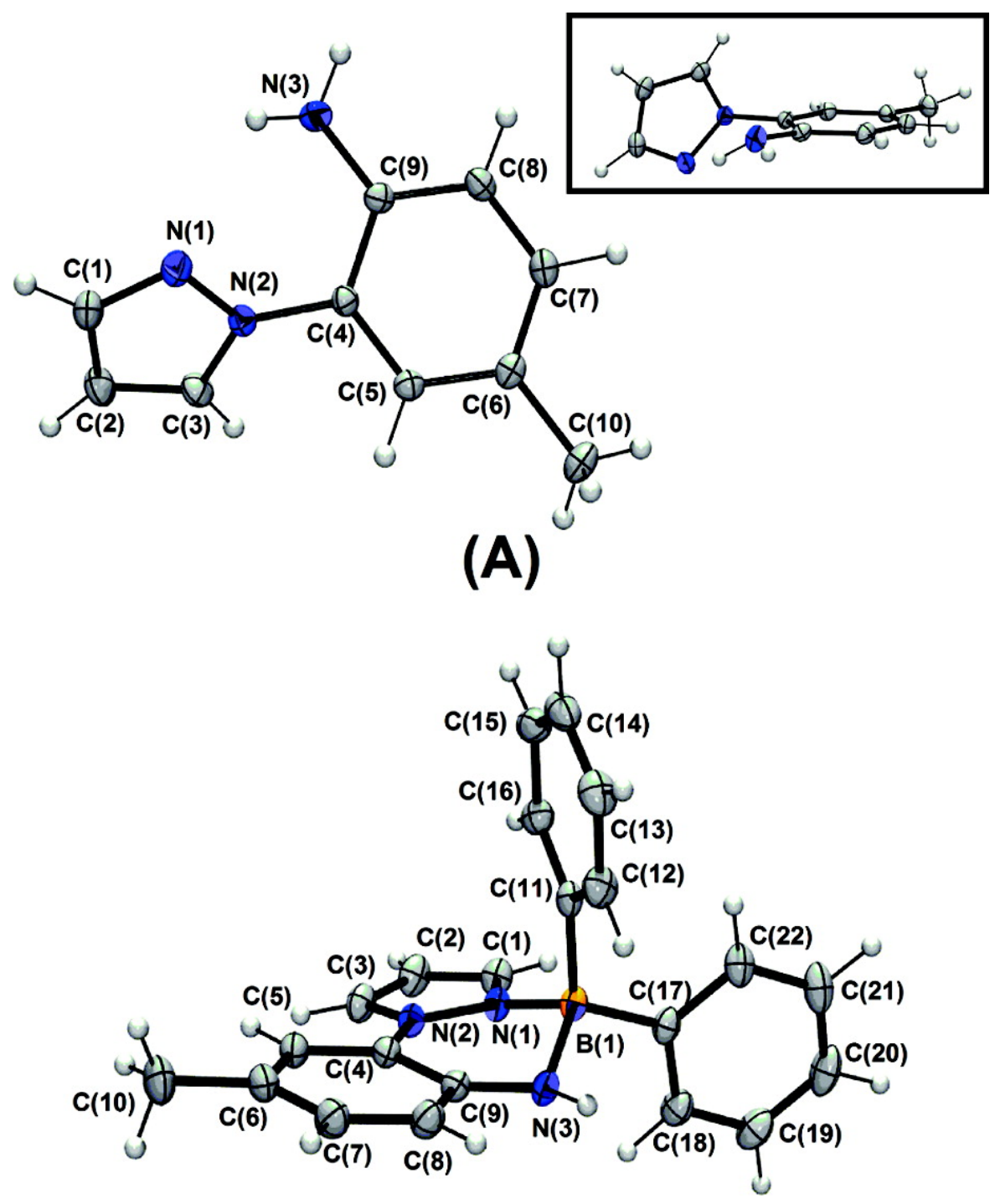

(B)

Figure 1 Molecular structures of (a) $\mathrm{H}($ pzAnMe) (L2) and (b) its BORAZAN derivative Ph2B(pzAnMe) (2) with atom labeling. Ellipsoids are shown at the 50\% probability level.

Table 1. Selected Bond Distances and Angles for $\mathrm{H}\left(\mathrm{pzAn}^{\mathrm{Me}}\right)$ (L2), $\mathrm{Ph}_{2} \mathrm{~B}\left(\mathrm{pzAn}{ }^{\mathrm{OMe}}\right)$ (1), $\mathrm{Ph}_{2} \mathrm{~B}\left(\mathrm{pzAn}{ }^{\mathrm{Me}}\right)$ (2), $\mathrm{Ph}_{2} \mathrm{~B}\left(\mathrm{pzAn}{ }^{\mathrm{CF}}\right)$ (6), and $\mathrm{Ph}_{2} \mathrm{~B}\left(\mathrm{pzAn}{ }^{\mathrm{CN}}\right)(7)^{a}$

\begin{tabular}{|llllll|}
\hline compound & $\mathrm{H}\left(\mathrm{pzAn}^{\mathrm{Me}}\right)$ & $\left(\mathrm{Ph}_{2} \mathrm{~B}\left(\mathrm{pzAn}{ }^{\mathrm{OMe}}\right)\right.$ & $\mathrm{Ph}_{2} \mathrm{~B}\left(\mathrm{pzAn}^{\mathrm{Me}}\right)$ & $\mathrm{Ph}_{2} \mathrm{~B}\left(\mathrm{pzAn}{ }^{\mathrm{CF}}\right)$ & $\mathrm{Ph}_{2} \mathrm{~B}\left(\mathrm{pzAn}{ }^{\mathrm{CN}}\right)$ \\
& $\mathrm{L} 2)$ & $(\mathbf{1})$ & $(\mathbf{2})$ & $(\mathbf{6})$ & $(\mathbf{7})$ \\
$\mathrm{B}-\mathrm{N}(1), \mathrm{pz}(\AA)$ & - & 1.597 & 1.601 & 1.604 & 1.605 \\
$\mathrm{~B}-\mathrm{N}(3), \mathrm{An}(\AA)$ & - & 1.538 & 1.537 & 1.537 & 1.538 \\
$\mathrm{~B}-\mathrm{C}(\mathrm{ax})(\AA)$ & - & 1.629 & 1.626 & 1.621 & 1.630 \\
$\mathrm{~B}-\mathrm{C}(\mathrm{eq})(\AA)$ & - & 1.613 & 1.611 & 1.615 & 1.624 \\
$\mathrm{HN}-\mathrm{C}(1)(\AA)$ & 1.386 & 1.390 & 1.388 & 1.365 & 1.354 \\
$\Sigma \angle$ 's about N$(3)$ & 344.73 & 343.76 & 344.22 & 350.84 & 353.08 \\
$\mathrm{C}(4)-\mathrm{C}(9)(\AA)$ & 1.405 & 1.410 & 1.401 & 1.408 & 1.422 \\
$\mathrm{C}(8)-\mathrm{C}(9)(\AA)$ & 1.401 & 1.392 & 1.405 & 1.406 & 1.411 \\
\hline
\end{tabular}




\begin{tabular}{|llllll|}
\hline $\mathrm{C}(4)-\mathrm{C}(5)(\AA)$ & 1.392 & 1.391 & 1.394 & 1.386 & 1.378 \\
$\mathrm{C}(7)-\mathrm{C}(8)(\AA)$ & 1.387 & 1.388 & 1.381 & 1.380 & 1.370 \\
$\mathrm{C}(5)-\mathrm{C}(6)(\AA)$ & 1.394 & 1.385 & 1.388 & 1.386 & 1.387 \\
$\mathrm{C}(6)-\mathrm{C}(7)(\AA)$ & 1.397 & 1.390 & 1.393 & 1.388 & 1.403 \\
$\mathrm{C}(4)-\mathrm{N}(2)(\AA)$ & 1.429 & 1.424 & 1.426 & 1.428 & 1.423 \\
$\mathrm{~N}(1) \cdots \mathrm{N}(3)(\AA)$ & 2.923 & 2.438 & 2.438 & 2.439 & 2.449 \\
$\perp \mathrm{B} \cdots(\mathrm{An})^{b}(\AA)$ & - & 0.819 & 0.810 & 0.762 & 0.630 \\
$\left.\left(\mathrm{~N}_{2} \mathrm{BN}\right)_{3}\right)^{-}(\mathrm{An})(\mathrm{deg})$ & - & 36.17 & 35.72 & 33.61 & 27.72 \\
$\left(\mathrm{~N}_{1} \mathrm{BN}\right)^{d}-(\mathrm{An})(\mathrm{deg})-$ & 45.03 & 44.80 & 43.86 & 37.12 \\
$\mathrm{C}(5) \mathrm{C}(4)-\mathrm{N}(2) \mathrm{N}(1)(127.91$ & 166.35 & 167.02 & 167.92 & 170.49 \\
$\operatorname{deg})$ & & & & \\
$\mathrm{C}(9) \mathrm{C}(4)-\mathrm{N}(2) \mathrm{N}(1)(52.76$ & 14.17 & 13.63 & 14.73 & 12.23 \\
$\operatorname{deg})$ & & & & \\
$\mathrm{N}(2) \mathrm{C}(4)-\mathrm{C}(9) \mathrm{N}(3)(2.00$ & 1.20 & 0.72 & 3.05 & 2.55 \\
$\operatorname{deg})$ & & & & \\
$\mathrm{mpl}(\mathrm{pz})-(\mathrm{An})(\mathrm{deg})$ & 51.36 & 13.78 & 13.19 & 14.62 & 13.51 \\
\hline
\end{tabular}

${ }^{a}$ See Figure 1 for atom labeling. Also: $\mathrm{pz}=$ pyrazolyl; $\mathrm{An}=$ Aniline; $(\mathrm{An})=$ mean plane of $\mathrm{C}_{6} \mathrm{~N}$ aniline ring; $\mathrm{mpl}(\mathrm{pz})=$ mean plane of pyrazolyl ring. ${ }^{b}$ Distance of normal vector between mean aniline plane and boron. ${ }^{c}$ Angle between plane defined by $\mathrm{N}(2), \mathrm{B}(1), \mathrm{N}(3)$ and $(\mathrm{An}) .{ }^{d}$ Angle between plane defined by $N(1), B(1), N(3)$ and $(A n)$.

Further inspection of the structural ramifications of complexation shows several other features of relevance for understanding the properties of the current BORAZAN systems. By comparing the pzAn framework in the structures of $\mathbf{L 2}$ and $\mathbf{2}$, the most obvious and important difference is the increase in coplanarity between the pyrazolyl and aniline rings of the latter. While coplanarity could be measured using the dihedral angle between mean planes of the pyrazolyl and aniline rings $\left(13.2^{\circ}\right.$ in 2 versus $51.4^{\circ}$ in L2), there is no clear trend correlating this angle with other structural features in the BORAZAN series 1, 2, 6, and $\mathbf{7}$ because this dihedral is the sum of several possible ligand distortions, shown in Figure 2. The major contributor to the dihedral angle is pyrazolyl ring-twisting (bottom of Figure 2), described best by the $\mathrm{C}(5) \mathrm{C}(4)-\mathrm{N}(2) \mathrm{N}(1)$ torsion angle (see Figure 1 for atom labeling) which is ideally $180^{\circ}$ for coplanarity. As anticipated from the other structural features such as the decrease in chelate ring-puckering with increasing electron-withdrawing capabilities of the para-X substituents in the BORAZANs, pyrazolyl ring-twisting becomes less pronounced (more coplanar with the aniline ring) along the series. Thus, the torsion angle increases in the following order: $166.4^{\circ}$ $(\mathrm{X}=\mathrm{OMe})<167.0^{\circ}(\mathrm{X}=\mathrm{Me})<167.9^{\circ}\left(\mathrm{X}=\mathrm{CF}_{3}\right)<170.5(\mathrm{X}=\mathrm{CN})$. Another possible torsion angle that could describe pyrazolyl ring-twisting, $\mathrm{C}(9) \mathrm{C}(4)-\mathrm{N}(2) \mathrm{N}(1)$ (where a torsion of $0^{\circ}$ would constitute coplanarity), is a less desirable descriptor since this angle is directly modified by another commonly observed distortion derived from out-of-plane ('oop') bending of the aniline ring (top right of Figure 2). The $\mathrm{N}(2) \mathrm{C}(4)-\mathrm{C}(9) \mathrm{N}(3)$ torsion angle of any value other than the ideal $0^{\circ}$ denotes out-of-plane ('oop') distortion in the ligand framework, occurring for either or both pyrazolyl or aniline-nitrogen moieties. This torsion varies between $0.72^{\circ}$ for 2 and $3.05^{\circ}$ for 7 but with no obvious trend. The 'oop' distortion is clearly a minor but significant contributor to the pyrazolyl-aniline dihedral angle. Interestingly if the 'oop' torsion angle is subtracted from the alternate pyrazolyl ring-twisting torsion, $\mathrm{C}(9) \mathrm{C}(4)-\mathrm{N}(2) \mathrm{N}(1)$, or from the dihedral angle of mean pyrazolyl and aniline planes of a given compound, the collection of resultant angles corroborates the trend that increasing electron-withdrawing power of the para-aniline substituent increases the coplanarity of the nitrogen-containing rings in the BORAZAN series. Finally, it should be noted that the distance between the aniline nitrogen and the remote 
pyrazolyl nitrogen, $\mathrm{N}(3) \cdots \mathrm{N}(1)$ in Figure 1 , which is a crude measure of the 'bite' of the chelate remains fairly constant at about $2.44 \AA$ in the BORAZAN series. The minor increase in this distance observed for $\mathbf{7}$ compared to $\mathbf{1}$, for instance, is likely due to the slightly shorter $\mathrm{C}(9)-\mathrm{N}(3)$ bond and the minor geometric changes associated with the slightly greater degree of coplanarity in the ligand system.

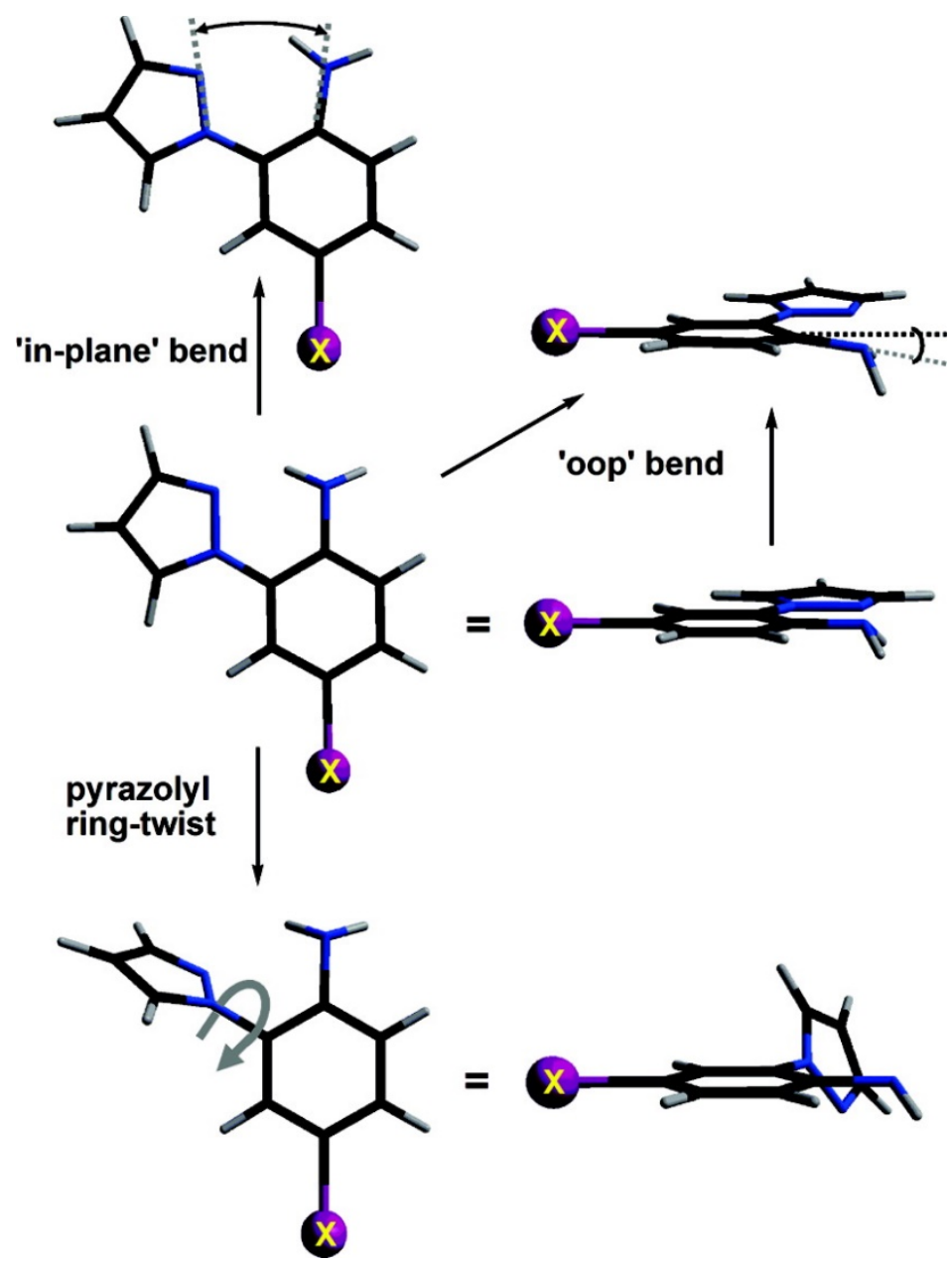

Figure 2 Common distortions in the 2-(pyrazolyl)aniline ligand framework.

NMR. The NMR spectral data for the BORAZANs in various solvents indicate that the compounds are stereochemically nonrigid in solution. As discussed above, the solid-state structures have only $C_{1}$ symmetry where the phenyl groups on boron are symmetrically nonequivalent and can be labeled as either 'axial' or 'equatorial'. However, the room temperature ${ }^{1} \mathrm{H}$ NMR spectra gave only one set of resonances for boron- phenyl rings rather than two sets (axial, equatorial) as would be expected if the solid-state structures persisted in solution. Thus, in solution, a dynamic process exchanges the symmetrically nonequivalent phenyl groups, giving rise to an apparently more symmetrical species (an average structure with presumably overall $C_{s}$ symmetry). Also, since the ${ }^{11} \mathrm{~B}$ NMR spectra of all the BORAZANs showed only one set of relatively narrow signals $\left(w_{1 / 2} \sim 350 \mathrm{~Hz}\right)$ near $0 \mathrm{ppm}$ (relative to $\mathrm{BF}_{3} . \mathrm{OEt}_{2}$ ), consistent with four-coordinate boron (resonances for three-coordinate boron typically occur more downfield above about $+25 \mathrm{ppm}),{ }^{13}$ we tentatively assign this dynamic process as being due to a low-energy ring flipping process (with amine inversion). The dynamic process was still at the fast exchange limit even at $-80^{\circ} \mathrm{C}$ in toluene- $d_{8}$. Finally, in the series of ligands L1-L7 or the BORAZANs 1-7, there was a decent correlation between the 
primitive Hammett parameter, $\sigma_{p}$, of the aniline's para-X substituent and the chemical shift of the $\mathrm{NH}$ resonance (Supporting Information); the more electron-withdrawing the substituent (i.e., the more positive $\sigma_{p}$ ), the more downfield (deshielded) is the $\mathrm{NH}$ resonance. This trend is also anticipated from the previous structural discussion regarding the stereochemical activity of the aniline-nitrogen lone pair in the BORAZANs.

Computational Studies. Time-dependent density functional calculations (B3LYP/6-31G*, SPARTAN06) ${ }^{14}$ performed on PM3 energy-minimized structures of the free $\mathrm{H}\left(\mathrm{pzAn}^{\mathrm{X}}\right)$ ligands, L1-L7, and BORAZAN dyes, 1-7, were investigated in order to lend insight into the nature of the electrochemical and photophysical properties of the compounds. The frontier orbitals for a representative ligand, L2, and the corresponding BORAZAN, 2, are given in Figure 3, and complete results for all compounds can be found in the Supporting Information. For each compound, the orbitals from $\mathrm{HOMO}(-5)$ to $\mathrm{LUMO}(+5)$ and the lowest-energy excitations (that correspond to the three-lowest energy absorption bands) were calculated (Supporting Information). A comparison of the calculated energy levels for each series of compounds is given in Figure 4 while the calculated wavelength and oscillator strength of the lowest-energy transition for each compound are given in Table 3. For all L1-L7 and 1-7, the $\mathrm{HOMO}$ is mainly the nonbonding representation of the aniline-centered $\pi$-system, encompassing the aniline's nitrogen-centered lone pair. There is also a significant ( $\pi-$ antibonding) contribution from the para-aniline substituent's orbitals to the HOMO, in cases except $\mathbf{L} \mathbf{3}$ and $\mathbf{3}$ where $\pi$-interactions (of an $\mathrm{H}$ substituent) are impossible. Inspired by the seminal work of Kasha and Rawls on the photophysics of aniline derivatives ${ }^{15}$ it is convenient to refer to the HOMO (and other frontier orbitals containing significant contributions from the conjugated aniline lone pair) as a $\Pi\llcorner$ ( $\pi$-lone-pair) orbital to distinguish it from a pure $\pi$ orbital since $\mathrm{C}-\mathrm{N}$ bond rotation, or other deviations from nonplanarity, could give rise to more nonbonding character of the nitrogen lone pair and drastically change the photophysics of the molecule. This $\Pi\llcorner$ distinction is also important since any electronic transitions involving such orbitals have characteristics $(\varepsilon$, oscillator strengths, excited-state lifetimes, solvatochromism, etc.) that are between that expected for either a pure $n-\pi^{*}$ or $\pi-\pi^{*}$ transition. ${ }^{15 b}$ When comparing the relative energy of the $\mathrm{HOMO}$ of a given $\mathrm{H}\left(\mathrm{pzAn}^{\mathrm{X}}\right)$ ligand with that for its corresponding BORAZAN (Figure 4), the latter is destabilized, owing to an additional antibonding $\pi$-interaction between the boron-bound carbons and the aniline nitrogen's p-orbital (best viewed in the diagrams found in the Supporting Information) that is not present in the former. Also from Figure 4 it is seen that, for a given series of ligands or complexes, there is a stabilization of the HOMO with an increase in electron-withdrawing character of the aniline's para-substituent. The LUMO of each compound is $\pi^{*}$ in character and spans the $\pi$-systems of both the aniline and the pyrazolyl rings with only a small contribution from the aniline nitrogen's conjugated p-orbital. Relative to the HOMO, there is only very small energy stabilization with increasing electron-withdrawing character of the para-aniline substituent across the series of either ligands or BORAZANs; the differential energy stabilization is the origin of the tunability of the absorption/emission processes in the series of dyes. For the ligands L1-L7, the $\mathrm{HOMO}(-5)$ to $\mathrm{HOMO}(-1)$ orbitals are $\pi$-bonding, the virtual orbitals LUMO $(+1)$ to LUMO $(+3)$ are $\pi^{*}$ antibonding, while the $\operatorname{LUMO}(+4)$ and $\operatorname{LUMO}(+5)$ are $\sigma^{*}$ antibonding. In the BORAZAN's, 1-7, new states arise due to the contributions from the diphenylboron moiety. Thus, four new m-orbitals located mainly on the boron-phenyls, $\mathrm{HOMO}(-1)$ to $\mathrm{HOMO}(-4)$, appear before the next-lowest pzAn-based mL-orbital, $\mathrm{HOMO}(-5)$. The corresponding four new $\pi^{*}$ orbitals include contributions from both the pzAn and diphenylboryl moieties and constitute the $\operatorname{LUMO}(+2)$ to $\operatorname{LUMO}(+5)$. 


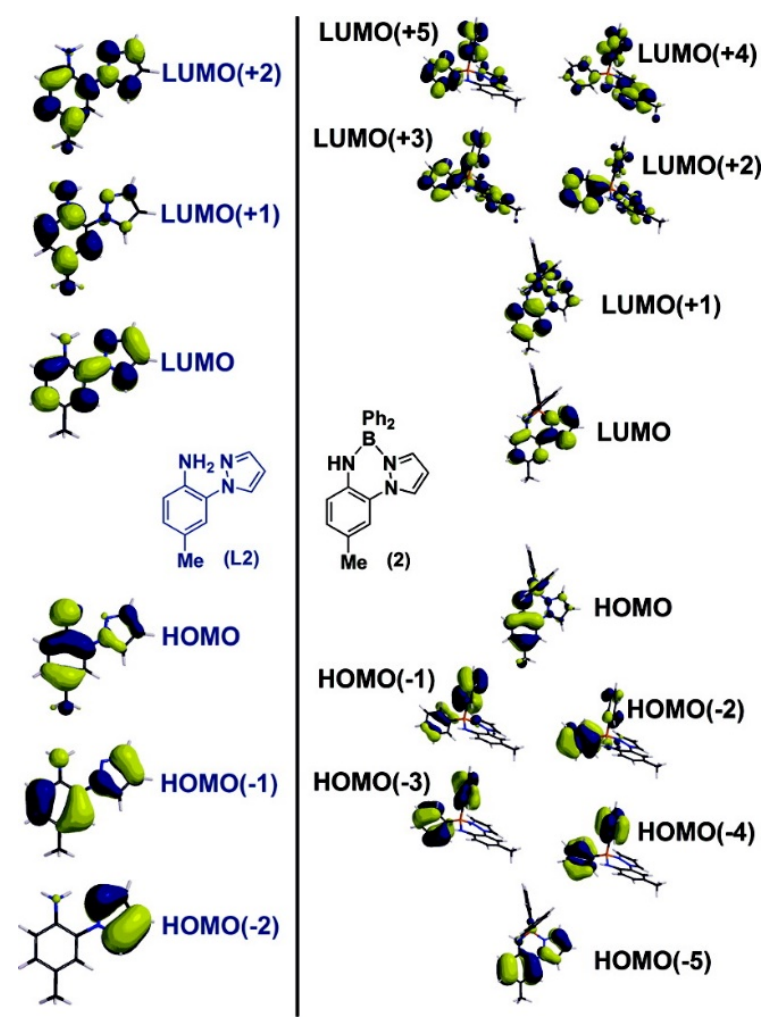

Figure 3 Frontier orbitals of $\mathrm{H}\left(\mathrm{pzAn}^{\mathrm{Me}}\right)$, L2, and its corresponding BORAZAN, 2, obtained from density functional (B3LYP/6-31G*) calculations.

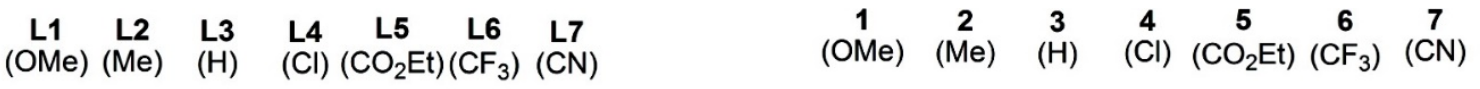

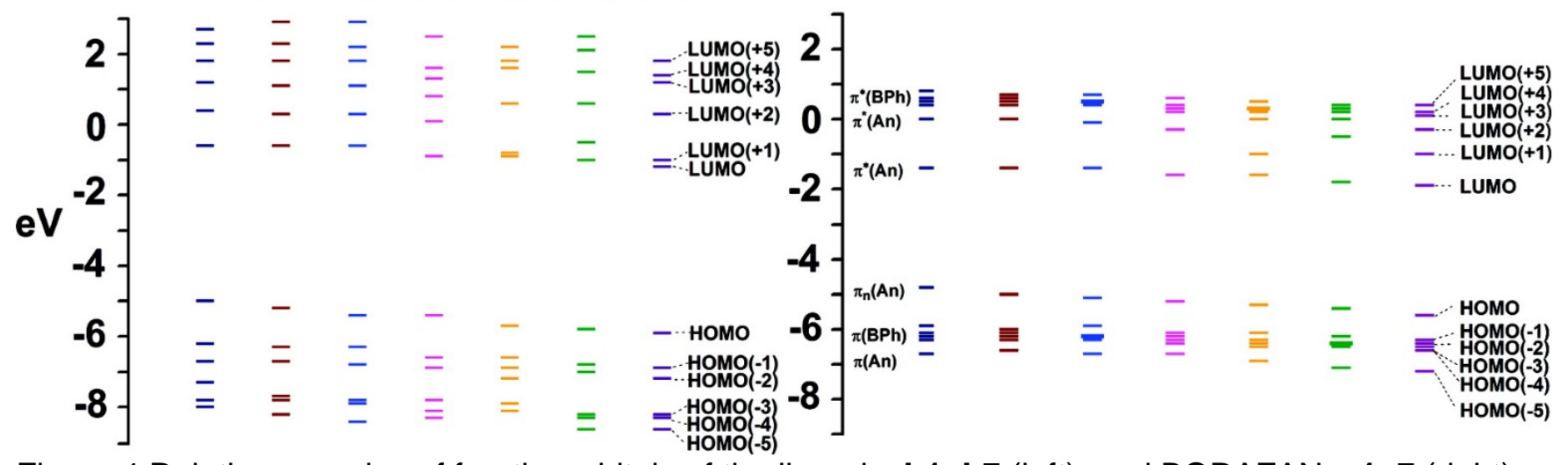

Figure 4 Relative energies of frontier orbitals of the ligands, L1-L7 (left), and BORAZANs, 1-7 (right) obtained from DFT (B3LYP/6-31G*) calculations.

The calculated absorption spectrum (Supporting Information) for each ligand and each BORAZAN qualitatively reproduced the experimentally observed spectrum in terms of both the number and intensity of expected bands, as well as trends within each series of compounds, but obvious differences in the absolute energies of bands (owing, in part, to deficiency in the solvation model) account for deviations from the experimentally observed results (vide infra). The calculated spectrum for each ligand consists of three bands while that of each BORAZAN consists of four bands. For the ligands, extensive mixing of states occurs. The lowest-energy excitation band was found to be mainly $\pi\left\llcorner-\Pi^{*}\right.$ due to the HOMO-LUMO transition with some contribution from an energetically accessible $\pi \mathrm{L}-\pi \mathrm{L}^{*}$ transition $[\mathrm{HOMO}(-1)-\mathrm{LUMO}(+1)]$. Similarly, the remaining two bands were extensively mixed but were 
mainly $\pi-\pi^{*}$ in character with minor contributions from the HOMO-LUMO $(+N)(N=1-3)$. The BORAZAN spectra were better behaved. The lowest energy excitation was due to the pure HOMO-LUMO transition, as might be anticipated. The next higher-energy excitation band was calculated to be $\pi$ (boron phenyl) $-\Pi^{*}(p z A n)$ in character and is composed of four overlapping $\mathrm{HOMO}(-\mathrm{N})$-LUMO $(N=1-4)$ transitions. The third highest energy excitation band originates from HOMO-LUMO $(+N)(N=1-4)$ transitions and is therefore $\pi\left\llcorner-\pi^{*}\right.$ in character and had a much higher intensity than the lowest-energy bands. Presumably, the highest energy band would mainly be $\pi-\pi^{*}$ in character because of the numerous closely spaced $\mathrm{HOMO}(-\mathrm{N})-\mathrm{LUMO}(+(\mathrm{N}+1))(\mathrm{N}=1-4)$ transitions involving the boron phenyl groups.

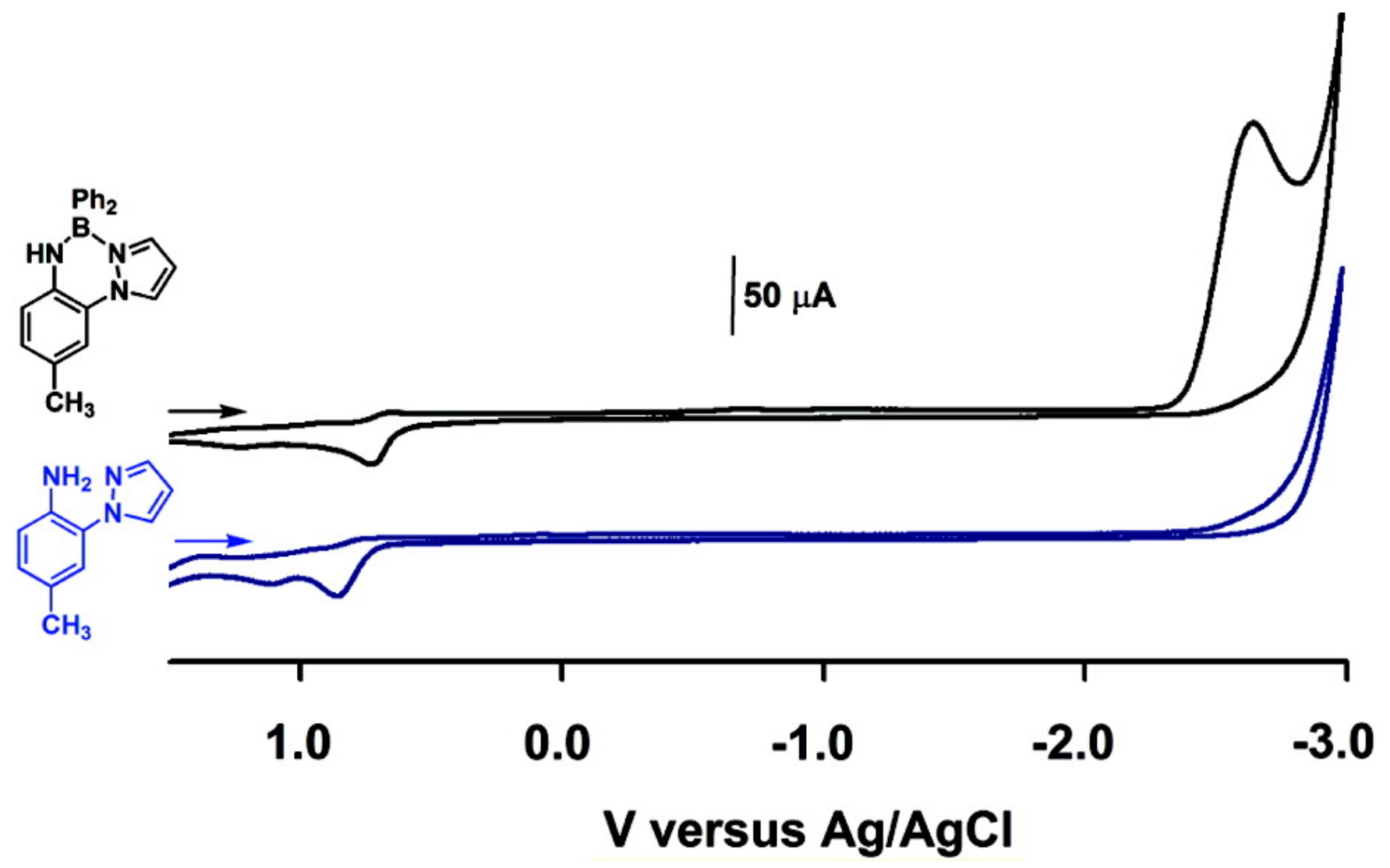

Figure 5 Cyclic voltammograms (100 mV/s) of $\mathrm{CH}_{3} \mathrm{CN}$ solutions of $\mathrm{H}\left(\mathrm{pzAn}{ }^{\mathrm{Me}}\right)$, $\mathbf{L 2}$ (blue, bottom), and $\mathrm{Ph}_{2} \mathrm{~B}\left(\mathrm{pzAn}{ }^{\mathrm{Me}}\right), 2$ (black, top), with $\mathrm{NBu}_{4} \mathrm{PF}_{6}$ as supporting electrolyte.

Voltammetry. Since the aniline moiety is a well-known electron donor, ${ }^{16}$ the electrochemistry of $\mathrm{CH}_{3} \mathrm{CN}$ and $\mathrm{CH}_{2} \mathrm{Cl}_{2}$ solutions of the ligands and BORAZANs were examined by cyclic voltammetry. The results of the electrochemical studies showed a decrease in oxidation potential for the BORAZAN versus a pzAn ligand and a decrease in oxidation potential with increasing electron-donating character of the para-aniline substituent, both explained by the destabilization of the HOMO as predicted by calculations. Representative voltammograms for $\mathrm{H}\left(\mathrm{pzAn}^{\mathrm{Me}}\right)$, L2 , and $\mathrm{Ph}_{2} \mathrm{~B}\left(\mathrm{pzAn}^{\mathrm{Me}}\right)$, 2, are given in Figure 5 while a summary of the data for the remaining compounds is provided in Table 2. Each ligand, L1-L7, undergoes an irreversible oxidation above about $0.8 \mathrm{~V}$ (depending on substituent), and the corresponding voltammogram is reminiscent of ECE-type behavior where the electrochemically generated species (which is yet to be identified) typically has a reversible oxidation. It should be noted that the oxidation of para-substituted aniline derivatives is known to be irreversible, giving mixtures of electrochemically active species (head-to-tail, tail-to-tail, and head-to-head dimers (both 
hydrazoaryls and diazoaryls) and other species such as diarylamines) whose composition depends on the experimental conditions and nature of substituents. ${ }^{17}$ The oxidation of a given BORAZAN complex is typically $150-300 \mathrm{mV}$ energetically more favorable than that of the corresponding free ligand and appears to be quasireversible (only in the case of 1 , does the oxidation appear reversible). As mentioned previously, for each series of ligands, L1-L7, or BORAZANs, 1-7, the oxidation becomes more favorable with increasing electron-donating ability of the aniline's para-substituent. Finally, a highly irreversible reduction (cathodic) wave is also observed in the voltammogram of each BORAZAN that is not typically present in that of the corresponding free ligand. This process is more favorable for derivatives with electronwithdrawing substituents occurring at ca. $-2.4 \mathrm{~V}$ (vs Ag/AgCl in acetonitrile; see Table 2 and Supporting Information) compared to that for derivatives with electron-donating substituents at $-2.6 \mathrm{~V}$, but the reduction potential is rather invariant with regard to the type of electronwithdrawing or -donating substituent. These results are consistent with the DFT calculations which indicated a stabilization of the LUMO of a given BORAZAN relative to the $\mathrm{H}(\mathrm{pzAn})$ but only a slight stabilization with electron-withdrawing character of the para-aniline substituent across a given series of compounds.

Table 2. Summary of Electrochemical Data for H(pzAn) Ligands and Diphenyl-BORAZAN Derivatives (See Supporting Information for voltammograms) ${ }^{a}$

\begin{tabular}{|c|c|c|}
\hline compound & \multicolumn{2}{|c|}{ oxid. (V) red. $(\mathrm{V})^{a}$} \\
\hline $\mathrm{H}\left(\mathrm{pzAn}^{\mathrm{OMe}}\right), \mathbf{L 1}$ & \multicolumn{2}{|c|}{$0.75,1.29$} \\
\hline $\mathrm{H}(\mathrm{pzAn} \mathrm{Me}), \mathrm{L} 2$ & \multicolumn{2}{|c|}{$0.87,1.11-$} \\
\hline H(pzAn), L3 & & - \\
\hline $\mathrm{H}(\mathrm{pzAn} C \mathrm{Cl}), \mathrm{L} 4$ & \multicolumn{2}{|c|}{$101116-$} \\
\hline $\mathrm{H}\left(\mathrm{pzAn} \mathrm{n}^{\mathrm{CO} 2 \mathrm{IEt}}\right), \mathbf{L} \mathbf{5}$ & \multicolumn{2}{|c|}{$\begin{array}{l}1.01,1.16- \\
1.17 .1 .31-2.56\end{array}$} \\
\hline$H\left(p^{\prime} A n^{C F}\right), \mathbf{L} \mathbf{6}$ & \multicolumn{2}{|c|}{$1.23,1.49-$} \\
\hline $\mathrm{H}\left(\mathrm{pzAn} \mathrm{n}^{\mathrm{CN}}\right), \mathbf{L 7}$ & 1.31 & -2.62 \\
\hline $\mathrm{Ph}_{2} \mathrm{~B}(\mathrm{pzAn} \mathrm{OMe}), \mathbf{1}$ & 0.53 & -2.59 \\
\hline $\mathrm{Ph}_{2} \mathrm{~B}\left(\mathrm{pzAn}{ }^{\mathrm{Me}}\right), 2$ & 0.69 & -2.59 \\
\hline $\mathrm{Ph}_{2} \mathrm{~B}(\mathrm{pzAn}), 3$ & 0.79 & -2.67 \\
\hline $\mathrm{Ph}_{2} \mathrm{~B}\left(\mathrm{pzAn} \mathrm{Cl}^{\mathrm{Cl}}\right), 4$ & 0.84 & -2.41 \\
\hline $\mathrm{Ph}_{2} \mathrm{~B}\left(\mathrm{pzAn} \mathrm{CO}^{\mathrm{COEt}}\right)$ & 51.07 & -2.40 \\
\hline $\mathrm{Ph}_{2} \mathrm{~B}\left(\mathrm{pzAn}^{\mathrm{CF} 3}\right), 6$ & 1.04 & -2.39 \\
\hline $\mathrm{Ph}_{2} \mathrm{~B}\left(\mathrm{pzAn}^{\mathrm{CN}}\right), 7$ & 1.12 & -2.42 \\
\hline
\end{tabular}

${ }^{a}$ Versus $\mathrm{Ag} / \mathrm{AgCl}$ scan rate of $100 \mathrm{mV} / \mathrm{s}$ in $\mathrm{CH}_{3} \mathrm{CN}$ with $\mathrm{NBu}_{4}(\mathrm{PF})_{6}$ as supporting electrolyte.

Electronic Spectra. The photophysical data for the ligands L1-L7 and BORAZAN complexes 1-7are collected in Table 3 and in the Supporting Information. The absorption spectrum of a representative free ligand, $\mathrm{H}\left(\mathrm{pzAn}^{\mathrm{CF} 3}\right), \mathbf{L} \mathbf{6}$, along with the absorption and emission spectra for the corresponding BORAZAN, $\mathrm{Ph}_{2} \mathrm{~B}\left(\mathrm{pzAn}{ }^{\mathrm{CF}} 3\right.$ ), 6 (each in $\mathrm{CH}_{3} \mathrm{CN}$ ), are given in Figure 6 . The absorption spectrum of each $\mathrm{H}\left(\mathrm{pzAn} \mathrm{n}^{\mathrm{X}}\right)$ ligand consists of three bands; one high-intensity, high-energy band at ca. $230 \mathrm{~nm}(\varepsilon \approx 26000)$, a second less intense band at ca. $250 \mathrm{~nm}(\varepsilon \approx 8600)$ (in some cases this band occurs as a shoulder to the high-energy band), and a low-energy, low-intensity band above about $300 \mathrm{~nm}(\varepsilon \approx 4500)$. With the BORAZANs, each band appears to undergo a bathochromic shift, and a new high-energy band appears as a shoulder near $200 \mathrm{~nm}$, presumably for the $\pi-\pi^{*}$ transitions involving the boron-phenyl groups. The apparent bathochromic shifts of the absorption bands in the BORAZANs, compared to those in the free ligand, were predicted from the calculations. Also, since the 
number of bands and their intensities correlate well with the calculated spectra, the calculated assignments for electronic transitions (addressed earlier) appear reasonable. It should be noted that in the case of $\mathbf{L 5}$, the rather large extinction coefficient for the first band is likely due to the near degeneracy of the LUMO and LUMO(+1) (in fact, slight energetic inversion; see Figure 4 and Supporting Information) giving rise to overlapping $\Pi\left\llcorner-\pi L^{*}\right.$ transitions and also possibly fortuitous overlap with the $n-\pi^{*}$ and other transitions involving the ethoxycarbonyl group. The low-energy absorption band of each BORAZAN exhibits slight negative solvatochromism, with a very small hypsochromic shift with increasing solvent polarizability ( $\leq 10 \mathrm{~nm}$ range over the series; toluene, $\mathrm{CH}_{2} \mathrm{Cl}_{2}, \mathrm{THF}, \mathrm{EtOH}, \mathrm{CH}_{3} \mathrm{CN}, \mathrm{DMF}$ ). There is a decent correlation (Supporting Information) between the onset of the lowest-energy absorption band (corresponding to the minimum HOMO-LUMO gap, $\mathrm{E}_{s^{0}}{ }^{0}$ ) and the Hammett parameter, $\sigma_{R},{ }^{12}$ which indicates a significant resonance effect is operative in this transition, $a$ trend that is also suggested from the density functional calculations. The more electron-rich para-aniline substituents and those with greater degrees of $\pi$-conjugation give rise to more red-shifted absorption bands. The extension of this lowest-energy absorption band into the violet region of the spectrum accounts for the pale yellow color of the BORAZAN derivatives 1-4with electrondonating groups; BORAZANs 5-7 and all ligands, L1-L7, are colorless.

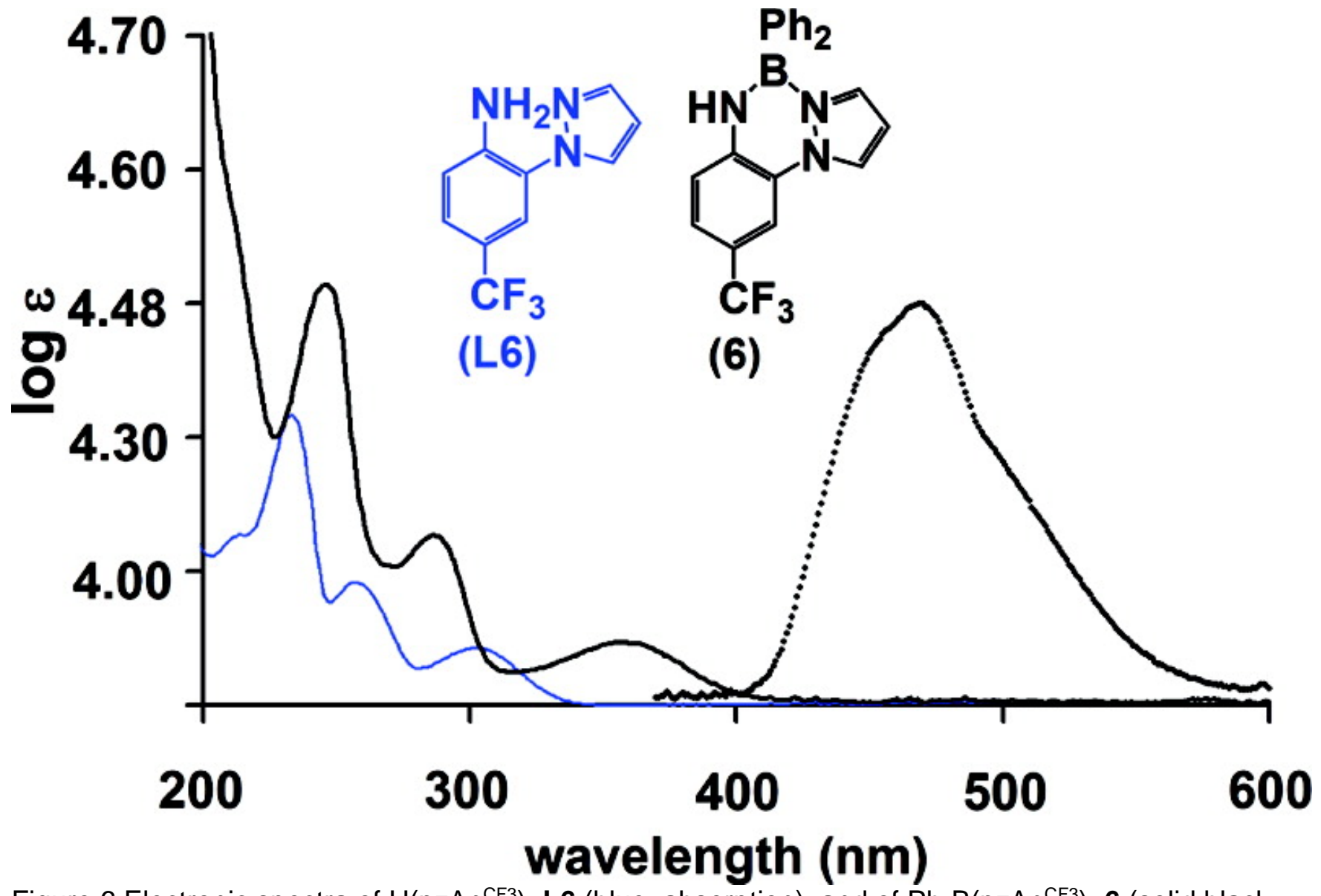

Figure 6 Electronic spectra of $\mathrm{H}\left(\mathrm{pzAn}^{\mathrm{CF} 3}\right)$, $\mathbf{L 6}$ (blue, absorption), and of $\mathrm{Ph}_{2} \mathrm{~B}\left(\mathrm{pzAn}^{\mathrm{CF} 3}\right), 6$ (solid black line, absorption; dotted black line, emission), in $\mathrm{CH}_{3} \mathrm{CN}$. 
Table 3. Selected Experimental and Calculated (TD-DFT B3LYP/6-31G*, SPARTAN06) Photophysical Properties of Ligands and BORAZAN Complexes

\begin{tabular}{|c|c|c|c|c|c|c|c|c|c|c|}
\hline comp & \multicolumn{8}{|c|}{ experimental } & \multicolumn{2}{|c|}{ calculated } \\
\hline d & ) & $\left.{ }^{-1} \mathrm{~cm}^{-1}\right)$ & ${ }^{0 b}(\mathrm{~nm}, \mathrm{eV})$ & ) & & ) & ) & & ) & $\begin{array}{l}\text { strength, } \\
f\end{array}$ \\
\hline L1 & 322 & 3300 & $357,3.48-$ & - & - & - & - & - & 318 & 0.1736 \\
\hline L2 & 311 & 4100 & $342,3.63-$ & - & - & - & - & - & 301 & 0.1879 \\
\hline L3 & 303 & 3400 & $334,3.71-$ & - & - & - & - & - & 268 & 0.1106 \\
\hline L4 & 317 & 4700 & $346,3.59-$ & - & - & - & - & - & 304 & 0.1830 \\
\hline L5 & 280 & 18000 & $316,3.93-$ & 371 & 0.01 & - & - & - & 294 & 0.1624 \\
\hline L6 & 305 & 3700 & $335,3.70-$ & - & - & - & - & - & 291 & 0.1836 \\
\hline L7 & 304 & 3700 & $340,3.65-$ & 367 & $\begin{array}{l}0.00 \\
7\end{array}$ & - & - & - & 296 & 0.1637 \\
\hline 1 & 386 & 4900 & $436,2.83478$ & 522 & 0.07 & 6.0 & 533 & $\begin{array}{l}0.00 \\
2\end{array}$ & 432 & 0.0755 \\
\hline 2 & 373 & 4400 & $418,2.98466$ & 488 & 0.58 & 7.5 & 508 & 0.03 & 413 & 0.0818 \\
\hline 3 & 364 & 7000 & $409,3.03466$ & 476 & 0.65 & 6.3 & 484 & 0.17 & 408 & 0.0734 \\
\hline 4 & 375 & 6600 & $419,2.96468$ & 480 & 0.69 & 8.8 & 483 & 0.51 & 417 & 0.0832 \\
\hline 5 & 358 & 6500 & $403,3.08447$ & 467 & 0.70 & 10.5 & 468 & 0.43 & 400 & 0.0844 \\
\hline 6 & 358 & 4700 & $405,3.12440$ & 468 & 0.66 & 15.9 & 476 & 0.49 & 405 & 0.0759 \\
\hline 7 & 366 & 4800 & $398,3.06447$ & 452 & 0.81 & 10.5 & 468 & 0.74 & 400 & 0.0856 \\
\hline
\end{tabular}

${ }^{a} \mathrm{CH}_{3} \mathrm{CN} .{ }^{b}$ Low-energy onset of absorption. ${ }^{c}$ Most intense band, solid. ${ }^{d}$ Most intense band, toluene. ${ }^{e}$ Degassed $(\mathrm{Ar}), \mathrm{CH}_{2} \mathrm{Cl}_{2}$.

Irradiation of the BORAZANs (either in the solid state or in hydrocarbon or halocarbon solution) with UV light results in intense emission that varies from blue for derivatives with electronwithdrawing para-aniline substituents to yellow-green for electron-donating substituents (Figure 7). With the exception of $\mathbf{L} \mathbf{5}$ and $\mathbf{L 7}$, which are only weakly emissive, the free ligands are nonluminescent. The fluorescence radiative de-excitation pathway was confirmed from the measured excited-state lifetimes which were between 6 and 16 ns. As seen in Table 3, the fluorescence quantum yields of the BORAZANs decrease with increasing electron-donating power of the para-aniline substituents $\left(\varphi_{F}\right.$ ranging from 0.81 for $\mathrm{Ph}_{2} \mathrm{~B}\left(\mathrm{pzAn}^{\mathrm{CN}}\right)(7)$ to 0.07 for $\mathrm{Ph}_{2} \mathrm{~B}\left(\mathrm{pzAn}{ }^{\mathrm{OMe}}\right.$ ) (1) in toluene). Such behavior may be anticipated from the energy gap law that predicts increased nonradiative decay rates for lower-energy transitions. ${ }^{18}$ Interestingly, the fluorescence quantum yields also show a significant dependence on solvent polarity, decreasing with increasing solvent polarity $\left(\varphi_{\mathrm{F}}\right.$ is 0.002 for $\mathbf{1}$ and 0.74 for 7 in $\mathrm{CH}_{3} \mathrm{CN}$ ). As seen in Table 3, the solvent-dependent drop-off in fluorescent quantum yields is more significant in the cases of $\mathbf{1 - 3}$ (with more electron-donating para-aniline substituents) than for 4-7. We tentatively attribute this behavior to the greater chemical reactivity of the former which, by interaction with solvent, may enhance losses predicted by the energy gap law; ${ }^{18} \mathrm{a}$ separate report by our group will further elaborate on this behavior. For a given BORAZAN, the solution emission is red-shifted relative to the solid-state emission (Figure 8) owing to solvent relaxation, ${ }^{19}$ and the emission bands are relatively broad $\left(\omega_{1 / 2}=70-80 \mathrm{~nm}\right)$ and are featureless for $\mathbf{1}$ and $\mathbf{2}$ but those for 3-7 show detectable fine structure. Deconvolution of the latter spectra using Gaussian fits with full-width-at-half-maximums between 40 and $80 \mathrm{~nm}$ (typical of organic luminophores) revealed three components comprising the fluorescence 
band of each BORAZAN (in the same solvent); the high-energy component is variably found between 440 and $460 \mathrm{~nm}$ (depending on substitution), the next lower-energy component is found between 465 and $480 \mathrm{~nm}$, and the lowest-energy band is found between 490 and 505 $\mathrm{nm}$. This fine structure may be vibronic in origin since apparent energy differences between the three components of the emission band match well with IR frequencies involving in-plane $\mathrm{N}-\mathrm{H}$ and $\mathrm{C}-\mathrm{H}\left(\right.$ pzAn) bending near $1300 \mathrm{~cm}^{-1}$ and those for coupled $\mathrm{B}-\mathrm{N}$ stretches and oop$\mathrm{C}-\mathrm{H}$ (BPh) bending motions near $700 \mathrm{~cm}^{-1} .{ }^{20}$ When investigating the solvent dependence of the emission, care is needed to avoid inadvertently overestimating the Stokes shift in 3-7, since the relative intensities of the components of the emission bands change with solvent polarity (Figure 8); the high-energy band predominates in solvents of low polarity while the medium-energy band becomes more intense at the expense of the former in more polar solvents. Each component of the fluorescent emission band, however, only undergoes a very slight bathochromic shift with increasingly polar solvents. In fact, by examining the high-energy component of the emission band by Lippert-Mataga plots ${ }^{21}$ of the Stokes shift versus solvent orientational polarizability parameter for each BORAZAN (shown for 7 in Figure 9), slopes on the order of $1100 \mathrm{~cm}^{-1}$ for each BORAZAN are obtained which are about $5-10 \%$ of the value found for other systems that exhibit significant intramolecular charge-transfer. ${ }^{22}$ This low value is expected in the current system since the extent of intramolecular charge-transfer associated with an $\Pi\left\llcorner-\Pi^{*}\right.$ transition should indeed be small due to the significant, but incomplete, overlap of the HOMO and LUMO, as the calculations suggest.

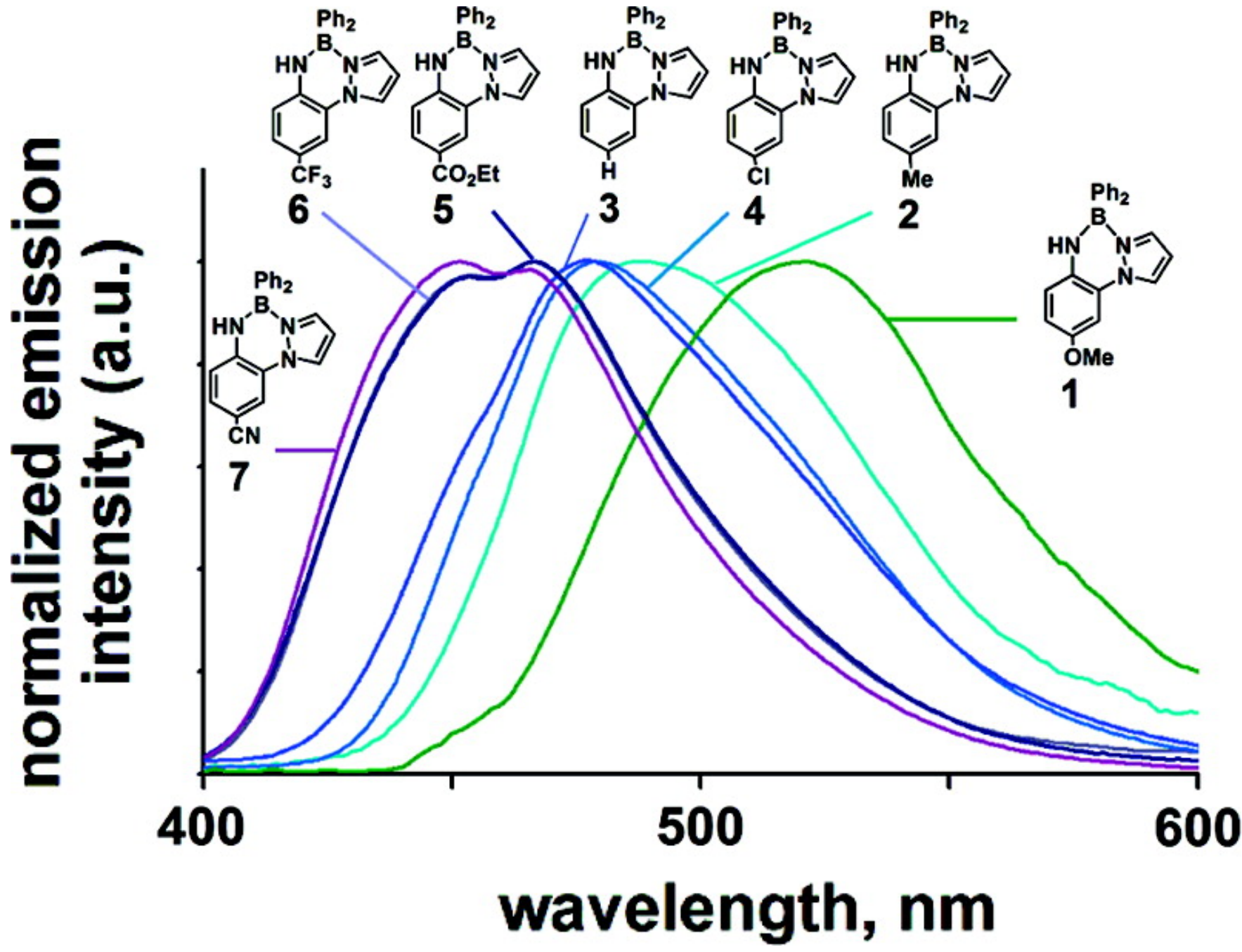

Figure 7 Overlay of normalized emission spectra of 1-7 obtained in toluene solution. 


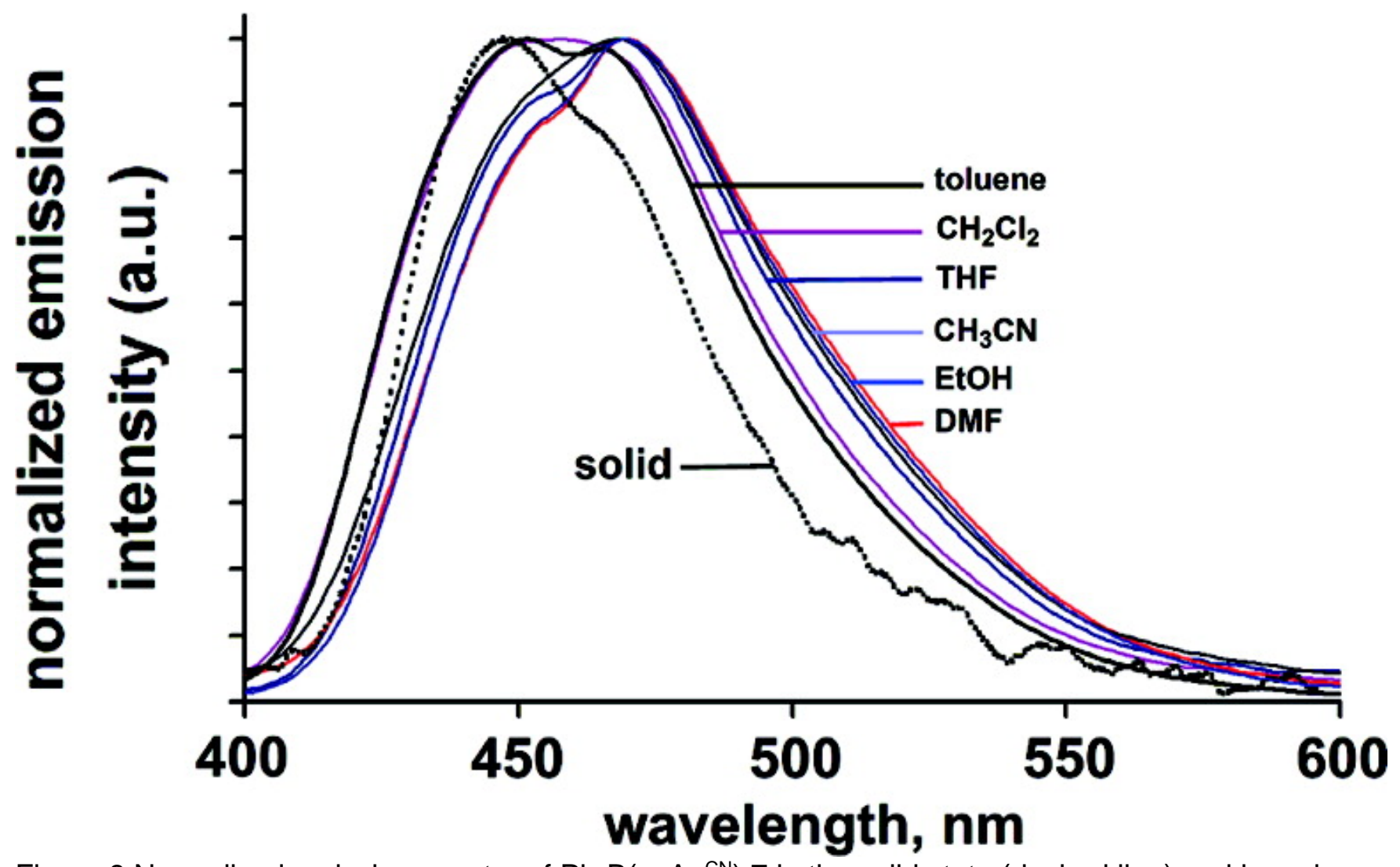

Figure 8 Normalized emission spectra of $\mathrm{Ph}_{2} \mathrm{~B}\left(\mathrm{pzAn}^{\mathrm{CN}}\right) 7$ in the solid state (dashed line) and in various solvents (solid lines). 


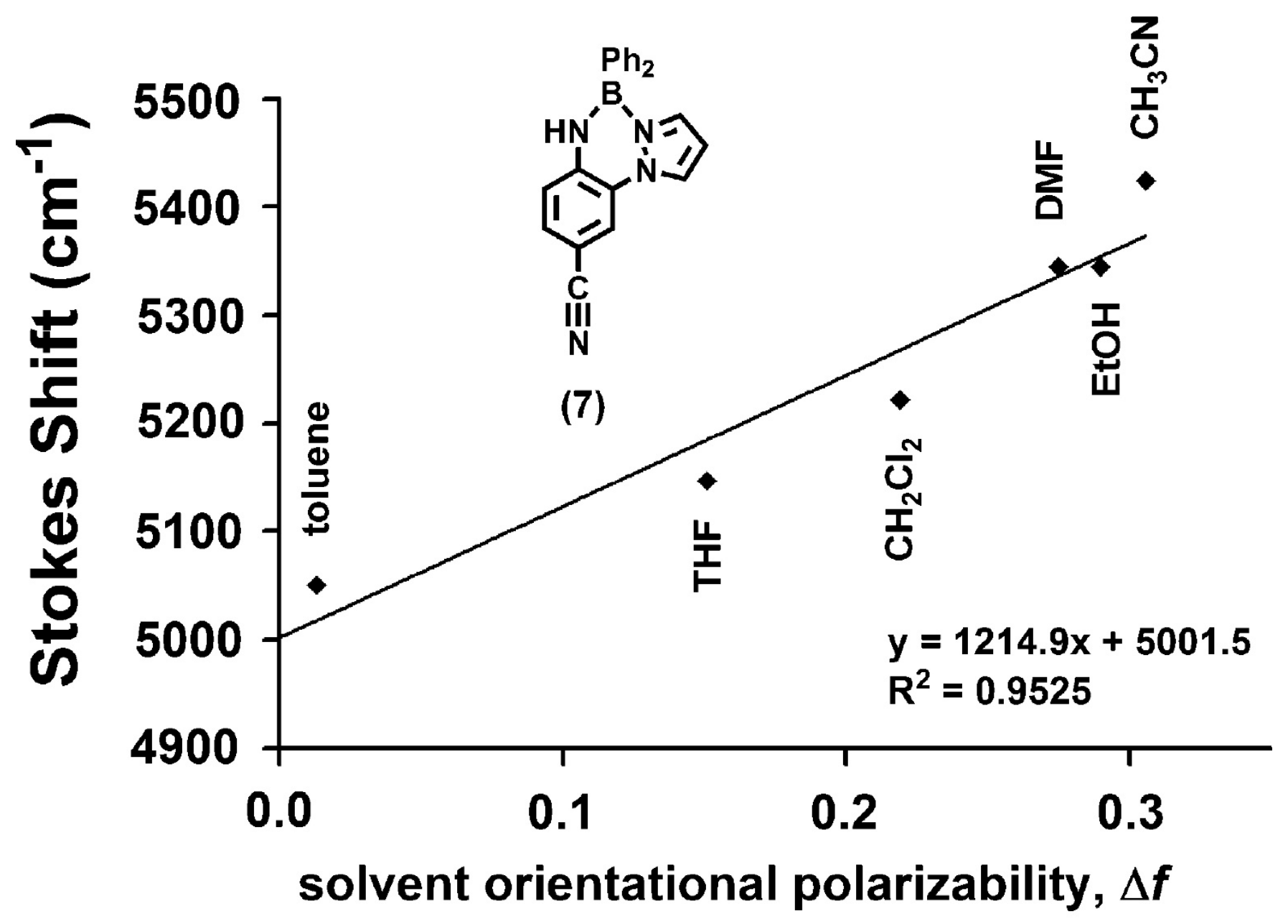

$$
\Delta f=\left(\frac{\varepsilon-1}{2 \varepsilon+1}\right)-\left(\frac{n^{2}-1}{2 n^{2}+1}\right) \begin{aligned}
& \varepsilon=\text { dielectric constant } \\
& n=\text { refractive index }
\end{aligned}
$$

Figure 9 Lippert-Mataga plot of Stokes shift versus solvent orientational polarizability parameter for a representative BORAZAN, Ph2B(pzAnCN) (7).

Summary. A new class of highly emissive fluorescent dyes based on the diphenylboron $\mathrm{N}, \mathrm{N}^{\mathrm{k}}$ chelate complexes of 2-(pyrazolyl)anilines has been prepared and extensively characterized by multiple methods. The results of X-ray crystallographic studies on the $\mathbf{L} 2$ and its boron complex 2revealed that chelation to the Lewis acidic diphenylboron moiety brings the pyrazolyl and aniline rings closer to coplanarity than found in the free ligand. Moreover, comparisons of intramolecular geometries in 1, 2, 6, and 7, which differ only in the para-aniline substituent, demonstrate greater 'quinoidal' distortion and an increased coplanarity between pyrazolyl and aniline rings with increasing electron-withdrawing character of the para-aniline substituent. It was also found that the electronic properties of the fluorescent dyes could be varied in a predictable manner by changing the electron-donating or withdrawing character of the paraaniline substituent. For instance, the color of emission could be tuned from blue to yellowgreen by increasing the substituent's electron-donating power. This change comes at a small expense in terms of fluorescent quantum yield and stability toward protonolysis by hydrogendonating solvents (alcohols, water), with the more electron-donating derivatives being most 
reactive and least luminous. The results of density functional calculations (B3LYP/6-31G*) qualitatively reproduced experimental observations and provided insight into the $\Pi\left\llcorner-\Pi^{*}\right.$ nature of the emission (where $\pi\llcorner$ indicates the special character of the $\pi$-system of the HOMO); the $\mathrm{HOMO}$ was found to be the nonbonding representation of the aniline-centered $\pi$-system that includes the nitrogen lone-pair while the LUMO extended over the $\pi$-system of both the pyrazolyl and aniline moieties. According to the calculations, the tunability of this first generation of BORAZAN dyes originates from the greater destabilization of the HOMO relative to the LUMO on increasing the electron-donating character of the para-aniline substituent. With the exception of 3, the aniline's para-substituent is involved in an antibonding m-interaction (not possible for 3 ) that destabilizes the HOMO to varying extent. Further destabilization of the $\mathrm{HOMO}$ arises due to an antibonding interaction between the boron-bound carbons and the porbital containing the aniline nitrogen lone-pair, which becomes more pronounced with increasing electron-donating character of the para-aniline substituent.

The ready availability of starting materials with nearly unlimited substitution patterns combined with the relative ease of dye synthesis render these and other pyrazolyl-aniline chelates very attractive potential luminophores for further investigation. Forthcoming reports from this group will demonstrate that simple structural modifications allow for a means to extend the emission range into the red and for providing a strategy to improve dye stability toward solvolysis.

\section{Experimental Section}

General Procedure for Ligand Syntheses (L1-L7). A mixture of the desired bromoaniline (1 equiv), pyrazole (1.2 equiv), $\mathrm{K}_{2} \mathrm{CO}_{3}$ (2.1 equiv), $20 \mathrm{~mol} \% \mathrm{~N}, N^{\prime}$-dimethylethylenediamine, and 5-10 $\mathrm{mL}$ of $p$-xylenes were degassed by three freeze/pump/thaw cycles. Under a nitrogen blanket, $5 \mathrm{~mol} \%$ Cul was added, and the resulting mixture was subject to two more freeze/pump/thaw cycles. The mixture was heated under nitrogen at reflux for $36 \mathrm{~h}$ (until starting materials were no longer detected by TLC). After cooling to room temperature, $100 \mathrm{~mL}$ of $\mathrm{H}_{2} \mathrm{O}$ and a few crystals of EDTA- $\mathrm{H}_{4}$ were added to facilitate workup. The mixture was extracted with three $100 \mathrm{~mL}$ portions of $\mathrm{CH}_{2} \mathrm{Cl}_{2}$ which were combined and dried over $\mathrm{MgSO}_{4}$ and filtered. The solvent was removed by rotary evaporation to leave oily residues. The residues were purified by column chromatography by using 4:1 hexanes:ethyl acetate as the eluent for all cases $\left(R_{\mathrm{f}} \mathrm{ca} .0 .4, \mathrm{SiO}_{2}\right.$ plate), except the trifluoromethyl derivative, for which methylene chloride was the eluent $\left(R_{\mathrm{f}}=0.4, \mathrm{SiO}_{2}\right.$ plate $)$. After column chromatography, all products were initially isolated as oils but could be crystallized (except for the $\mathrm{CF}_{3}$ derivative) by cooling supersaturated hexanes solutions (heated at reflux) to room temperature over the course of several hours. The trifluoromethyl derivative is a colorless oil at room temperature but crystallizes in a refrigerator. The amount of bromoaniline and pyrazole, the yields, and the characterization data for a representative ligand $\mathbf{L} \mathbf{1}$ is found below while details for L2-L7 can be found in the Supporting Information.

$\mathrm{H}\left(\mathrm{pzAn}{ }^{\mathrm{OMe}}\right)$, L1. With $0.856 \mathrm{~g}(4.24 \mathrm{mmol})$ 2-bromo-4-methoxy-aniline and $0.346 \mathrm{~g} \mathrm{(5.08}$ mmol) pyrazole, $0.601 \mathrm{~g}$ ( $75 \%$ yield) of L1 was obtained as colorless needles. Mp, $44-46{ }^{\circ} \mathrm{C}$. Anal. Calcd (obsd) for $\mathrm{C}_{10} \mathrm{H}_{11} \mathrm{~N}_{3} \mathrm{O}, \mathrm{C}, 63.48$ (63.07); H, 5.86 (5.66); 22.21 (21.95). ${ }^{1} \mathrm{H}$ NMR $\left(\mathrm{C}_{6} \mathrm{D}_{6}\right) \delta_{\mathrm{H}} 7.63(\mathrm{~d}, \mathrm{~J}=2 \mathrm{~Hz}, 1 \mathrm{H}), 7.20(\mathrm{~d}, \mathrm{~J}=1 \mathrm{~Hz}, 1 \mathrm{H}), 6.67(\mathrm{~s}, 1 \mathrm{H}), 6.52(\mathrm{~d}, 1 \mathrm{H}), 6.32(\mathrm{~d}, 1 \mathrm{H})$, 6.07 (dd, $J=2,1 \mathrm{~Hz}, 1 \mathrm{H}), 4.16(\mathrm{br} \mathrm{s}, 2 \mathrm{H}), 3.26(\mathrm{~s}, 3 \mathrm{H}) .{ }^{1} \mathrm{H}$ NMR $\left(\mathrm{CDCl}_{3}\right) \delta_{\mathrm{H}} 7.75(\mathrm{~d}, \mathrm{~J}=1 \mathrm{~Hz}$, $1 \mathrm{H}), 7.73(\mathrm{~d}, \mathrm{~J}=2 \mathrm{~Hz}, 1 \mathrm{H}), 6.80(\mathrm{~d}, \mathrm{~J}=8 \mathrm{~Hz}, 1 \mathrm{H}), 6.79(\mathrm{~s}, 1 \mathrm{H}), 6.70(\mathrm{~d}, \mathrm{~J}=8 \mathrm{~Hz} 1 \mathrm{H}), 6.46$ (dd, $J=2,1 \mathrm{~Hz}, 1 \mathrm{H}), 4.22$ (br s, 2H), 3.78 (s, 3H). ${ }^{13} \mathrm{C}$ NMR $\left(\mathrm{C}_{6} \mathrm{D}_{6}\right) \delta_{\mathrm{c}} 150.3,137.8,131.4$,

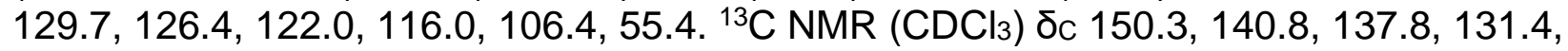
129.7, 126.4, 122.0, 116.0, 106.4, 55.4. UV-vis $\left(\mathrm{CH}_{3} \mathrm{CN}\right) \lambda_{\max } \mathrm{nm}\left(\varepsilon, \mathrm{M}^{-1} \mathrm{~cm}^{-1}\right) 200(21,000)$, 229 (16,000), 322 (3,300). IR (KBr pellet, $\left.\mathrm{cm}^{-1}\right)$ : 3743 VN-H str, 3421, 3350, 3135, 3118, 3001, 
2962, 2935, 2833, 1628 VN-H in-plane wag, 1595, 1518, 1452, 1396, 1340, 1290, 1261, 1227, 1180, $1111,1045,953,866,812,758,625 \mathrm{~V}_{\mathrm{N}-H o o p}$ wag.

General Procedure for Syntheses of Diphenylboron Derivatives, 1-7. Under nitrogen, an equimolar mixture of triphenylboron and the desired pyrazolyl aniline in $20-30 \mathrm{~mL}$ toluene were heated at reflux overnight. After cooling, solvent was removed by vacuum distillation to leave a glassy residue. Next, $25 \mathrm{~mL}$ of dried hexanes were added, and the mixture was heated under nitrogen with stirring to leave the desired compound as a powder. After cooling to room temperature, the mixture was separated by cannula filtration. The insoluble component was dried under vacuum. Additional crops of the BORAZAN could be obtained from the hexanesoluble components after concentration and cooling to give a precipitate that is collected by filtration and dried, as above. The quantities of reagents, isolated yields of powder, and characterization data of crystals (the characterization data of the powders and crystals were identical) are given below for $\mathbf{1}$ while the data for 2-7 are found in the Supporting Information.

$\mathrm{Ph}_{2} \mathrm{~B}$ (pzAn $\left.{ }^{\mathrm{OMe}}\right)$, 1. A mixture of $0.59 \mathrm{~g}(3.1 \mathrm{mmol}) \mathrm{L1}$ and $0.75 \mathrm{~g}(3.1 \mathrm{mmol})$ of $\mathrm{BPh}_{3}$ afforded $0.93 \mathrm{~g}(85 \%)$ of 1 as a yellow solid. Mp, $191-193{ }^{\circ} \mathrm{C}$, dec Anal. Calcd. (obsd.) for $\mathrm{C}_{22} \mathrm{H}_{20} \mathrm{BN}_{3} \mathrm{O}$ : C, 74.81 (74.36); H, 5.71 (5.81); N, 11.90 (11.69). ${ }^{1} \mathrm{H}$ NMR $\left(\mathrm{C}_{6} \mathrm{D}_{6}\right) \delta_{\mathrm{H}} 7.52$ (d, J = $\left.8 \mathrm{~Hz}, 4 \mathrm{H}\right)$, $7.33(\mathrm{dd}, \mathrm{J}=8,8 \mathrm{~Hz}, 4 \mathrm{H}), 7.23(\mathrm{t}, \mathrm{J}=8 \mathrm{~Hz}, 2 \mathrm{H}), 6.99(\mathrm{~d}, \mathrm{~J}=2 \mathrm{~Hz}, 1 \mathrm{H}), 6.57(\mathrm{~d}, J=2 \mathrm{~Hz}, 1 \mathrm{H})$, $6.52(\mathrm{dd}, J=8,8 \mathrm{~Hz}, 1 \mathrm{H}), 6.35(\mathrm{~d}, J=8 \mathrm{~Hz}, 1 \mathrm{H}), 6.22(\mathrm{~s}, 1 \mathrm{H}), 5.48(\mathrm{dd}, J=2,2 \mathrm{~Hz}, 1 \mathrm{H}), 3.78$ (br s, 1H), $3.21(\mathrm{~s}, 3 \mathrm{H}) .{ }^{13} \mathrm{C}$ NMR ( $\left.\mathrm{C}_{6} \mathrm{D}_{6}\right) \mathrm{dc}_{\mathrm{c}} 150.0,135.1,134.5,134.0,131.1,126.7,126.1$, 121.7, 119.1, 115.7, 106.5, 55.5. ${ }^{11} \mathrm{~B}$ NMR $\left(\mathrm{C}_{6} \mathrm{D}_{6}\right) \delta_{\mathrm{B}} 0.5 \mathrm{ppm}\left(\omega_{1 / 2}=491 \mathrm{~Hz}\right)$. UV-vis $\left(\mathrm{CH}_{3} \mathrm{CN}\right)$ $\lambda_{\max }, \mathrm{nm}\left(\varepsilon, \mathrm{M}^{-1} \mathrm{~cm}^{-1}\right): 197(46,000), 242(21,000), 292(3,800), 386(4900)$. IR (KBr pellet, $\mathrm{cm}^{-}$ 1): $3734 \mathrm{VN}-\mathrm{H}$ str, $3419 \mathrm{br}, 3396,3147,3130,3118,3086,3064,3020,3008,2966,2947,2928$, 2832, 1627 VN-H in-plane wag, 1518, 1458, 1433, 1385, 1365, 1342, 1316, 1292, 1271, 1238, 1215, 1190, 1141, 1138, 1097, 1045, 999, 985, 933, 926, 887, 870, 845, 810, 781, 760, 742, 706, $665,648,619 \mathrm{VN}-\mathrm{H}$ oop wag, 598, 561, 540.

\section{Acknowledgment}

J.R.G. thanks Marquette University, the Petroleum Research Fund (74371-G), and an NSF instrumentation grant (CHE-0521323) for support.

\section{References}

${ }^{1}$ Valeur, B. Molecular Fluorescence, Principles and Applications; Wiley-VCH: New York, 2002. ${ }^{2}$ (a) Haugland, R. P.; Kang, H. C. U.S. Patent 4,774,339, 1988. (b) Haugland, R. P. Handbook of Fluorescent Probes and Research Chemicals, 6th ed.; Molecular Probes: Eugene, OR, 1996. (c) Treibs, A.; Kreuzer, F.-H. Liebigs Ann. Chem. 1968, 718, 208.

${ }^{3}$ Boyer, J. H.; Haag, A. M.; Sathyamoorthi, G.; Soong, M. L.; Thangaraj, K.; Pavlopoulos, T. G. Heteroat. Chem. 1993, 4, 39.

${ }^{4}$ (a) Desvergne, J.-P., Czarnik, A. W., Eds. Chemosensors of Ion and Molecule Recognition; Kluwer: Dordrecht, the Netherlands, 1997. (b) Beer, G.; Niederalt, C.; Grimme, S.; Daub, J. Angew. Chem., Int. Ed. 2000, 39, 3252. (c) Kollmannsberger, M.; Rurack, K.; Resch-Genger, U.; Daub, J. J. Phys. Chem. A 1998, 102, 10211. (d) Kollmannsberger, M.; Gareis, T.; Heinl, S.; Breu, J.; Daub, J. Angew. Chem., Int. Ed. 1997, 36, 1333.

${ }^{5}$ For example: Zeng, L.; Miller, E. W.; Pralle, A.; Isacoff, E. Y.; Chang. C. J. J. Am. Chem. Soc. 2006, 128, 10. 
${ }^{6}$ (a) Hattori, S.; Ohkubo, K.; Urano, Y.; Sunahara, H.; Nagano, T.; Wada, Y.; Tkachenko, N. V.; Lemmetyinen, H.; Fukuzumi, S. J. Phys. Chem. B 2005, 109, 15368. (b) Imahori, H.; Norieda, H.; Yamada, H.; Nishimura, Y.; Yamazaki, I.; Sakata, Y.; Fukuzumi, S. J. Am. Chem. Soc. 2001,123, 100. (c) Wagner, R. W.; Lindsey, J. S. Pure Appl. Chem. 1996, 68, 1373.

7For example: (a) McDonnell, S. O.; O' Shea, D. F. Org. Lett. 2006, 8 (16), 3493. (b) Chen, T.R.; Chien, R.-H.; Jan, M.-S.; Yeh, A.; Chen, J.-D. J. Organomet. Chem. 2006, 691, 799. (c) Liu, Q. D.; Mudadu, M. S.; Thummel, R.; Tao, Y.; Wang, S. Adv. Funct. Mater. 2005, 15 (1), 143. (d) Chen, H.-Y.; Chi, Y.; Liu, C.-S.; Yu, J.-K.; Cheng, Y.-M.; Chen, K.-S.; Chou, P.-T.; Peng, S.-M.; Lee, G.-H.; Carty, A. J.; Yeh, S.-J.; Chen, C.T.Adv. Funct. Mater. 2005, 15, 567. (e) Park, N. G.; Lee, J. E.; Park, Y. H.; Kim, Y. S. Synth. Met. 2004, 145, 279. (f) Kaplan, G. M.; Frolov, A. N.; Rtishchev, N. I.; El'tsov, A. V. Zhur. Organ. Khim. 1991, 27, 872. (g) Kaplan, G. M.; Frolov, A. N.; Rtishchev, N. I.; El'tsov, A. V.; Ponomareva, T. K. Zhur. Obsch. Khim. 1991, 61, 1810. (h) Cui, Y.; Liu, Q.-D.; Bai, D. R.; Jia, W.-L.; Tao, Y.; Wang, S. Inorg. Chem. 2005, 44, 601. (i) Qin, Y.; Kiburu, Y.; Shah, S.; Jäkle, F. Org. Lett. 2006, 8, 5227.

${ }^{8}$ (a) Antilla, J. C.; Baskin, J. M.; Barder, T. E.; Buchwald, S. L. J. Org. Chem. 2004, 69, 5578. (b) Cristau, H.-J.; Cellier, P. P.; Spindler, J.-F.; Taillefer, M. Eur. J. Org. Chem. 2004, 695-709. (c) Taillefer, M.; Xia, N.; Ouali, A. Angew. Chem., Int. Ed. 2007, 46, 934. (e) Christau, H.-J.; Cellier, P. P.; Spindler, J.-F.; Taillefer, M.Chem. Eur. J 2004, 10, 5607. (f) See, also, Lindley, J. M.; McRobbie, I. M.; Meth-Cohn, O.; Suschitzky, H. J. Chem. Soc., Perkin Trans. 1 1980, 4, 982.

${ }^{9}$ (a) Mukherjee, A.; Subramanyam, U.; Puranik, V. G.; Mohandas, Sarkar, A. Eur. J. Inorg. Chem. 2005, 1254. (b) Piers, W. E.; Bourke, S. C.; Conroy, K. D. Angew. Chem., Int. Ed.2005, 44, 5016. (c) Saha, N.; Saha, A.; Chaudhuri, S.; Mak, T. C. W.; Banerjee, T.; Roychoudhury, P. Polyhedron 1992, 11, 2341.

${ }^{10}$ (a) Tidwell, J. H.; Buchwald, S. L. J. Am. Chem. Soc. 1994, 116, 11797. (b) Tobe, Y.; Utsumi, N.; Kawabata, K.; Nagano, A.; Adachi, K.; Araki, S.; Sonoda, M.; Hirose, K.; Naemura, K. J. Am. Chem. Soc. 2002, 124, 5350.

${ }^{11}$ Kelley, W. S.; Monack, L.; Rogge, P. T.; Schwartz, R. N.; Varimbi, S. R.; Walter, R. I. Liebigs Ann. Chem.1971, 744, 129.

${ }^{12}$ Isaacs, N. Physical Organic Chemistry, 2nd ed.; Longman Scientific and Technical: Essex, 1995; Chapter 4.

${ }^{13}$ (a) Phillips, W. D.; Miller, H. C.; Muetterties, E. L. J. Am. Chem. Soc. 1959, 81, 4496. (b) Beachley, O. T., Jr. J. Am. Chem. Soc. 1970, 92, 5372. (c) Wrackmeyer, B.; Nöth, H. Chem. Ber. 1977, 110, 1086.

${ }^{14}$ Shao, Y.; et. al. Phys. Chem. Chem. Phys. 2006, 8, 3172.

${ }^{15}$ (a) Kasha, M.; Rawls, R. Photochem. Photobiol. 1968, 7 (6), 561. (b) As these author's point out, an $\mathrm{n}-\Pi^{*}$ transition in hindered aromatic amines or in $\mathrm{N}$-heterocycles refers to electronic transitions from the lone pairs occupying orbitals orthogonal to the $\pi$-system (as found in pyridine, for instance) to the appropriate m-system orbital.

${ }^{16}$ (a) Galus, Z.; Adams, R. N. J. Phys. Chem. 1963, 67, 862. (b) Bacon, J.; Adams, R. N. J. Am. Chem. Soc. 1968, 90, 6596. (c) Hand, R. L.; Nelsen, R. F. J. Am. Chem. Soc. 1974, 96, 850. (d) MacDiarmid, A. G.; Epstein, A. J. Faraday Discuss. Chem. 
Soc. 1989, 88, 317. (e) MacDiarmid, A. G. Angew. Chem., Int. Ed. 2001, 40, 2581. (f) Heeger, A. J. Angew. Chem., Int. Ed. 2001, 40, 2591.

${ }^{17}$ (a) Sharma, L. R.; Manchanda, A. K.; Singh, G.; Verma Ranjit, S. Electrochim.

Acta 1982, 27 (2), 223. (b) Daniels, D. G. H.; Naylor, F. T.; Saunders, B. C. J. Chem. Soc. 1951, 3433.

${ }^{18}$ (a) Caspar, J. V.; Sullivan, B. P.; Kober, E. M.; Meyer, T. J. Chem. Phys. Lett. 1982, 91 (2),

91. (b) Penner, A. P.; Siebrand, W.; Zgierski, M. Z. J. Chem. Phys. 1978, 69 (12), 5496.

(c) Englman, R.; Jortner, J. Mol. Phys. 1970, 18 (2), 145.

${ }^{19}$ Jager, W. F.; Volkers, A. A.; Neckars, D. C. Macromolecules 1995, 28, 8153.

${ }^{20}$ (a) Williams, V.; Hofstadter, R.; Herman, R. C. J. Chem. Phys. 1939, 7, 802. (b) Ginsburg, N.; Matsen, F. A. J. Chem. Phys. 1945, 13 (5), 167. (c) Weyssenhoff, Kraus, F.J. Chem. Phys. 1971, 54 (6), 2387.

${ }^{21}$ (a) Mataga, N.; Kaifu, Y.; Koizumi, M. Bull. Chem. Soc. Jpn. 1956, 29, 465. (b) Lippert, E. Z. Naturforsch. Teil A 1955, 10, 541.

${ }^{22}$ (a) Mishra, A.; Behera, B. G.; Krishna, M. M. G.; Periasamy, N. J. Luminescence 2001, 92, 175. (b) Mutai, T.; Cheon, J.-D.; Arita, S.; Araki, K. J. Chem. Soc., Perkin Trans. 2001, 2, 1045. (c) Krebs, F. C.; Spanggaard, H. J. Org. Chem. 2002, 67, 7185. (d) Strehmel, B.; Sarker, A. M.; Malpert. J. H.; Strehmel, V.; Seifert, H.; Neckars, D. C. J. Am. Chem. Soc. 1999, 121, 1226. 